\title{
Tyrosine Hydroxylase Neurons Regulate Growth Hormone Secretion via Short-Loop Negative Feedback
}

\author{
${ }^{\circledR}$ Frederick Wasinski, ${ }^{1}$ João A.B. Pedroso, ${ }^{1}$ Willian O. dos Santos, ${ }^{1}$ Isadora C. Furigo, ${ }^{1}{ }^{\oplus}$ David Garcia-Galiano, ${ }^{2}$ \\ Carol F. Elias, ${ }^{2}{ }^{\circledR}$ Edward O. List, ${ }^{3}{ }^{\circledR}$ John J. Kopchick, ${ }^{3}{ }^{\circledR}$ Raphael E. Szawka, ${ }^{4}$ and ${ }^{\circledR}$ Jose Donato Jr ${ }^{1}$ \\ ${ }^{1}$ Departamento de Fisiologia e Biofísica, Instituto de Ciências Biomédicas, Universidade de São Paulo, São Paulo, SP Brazil, 05508000, ${ }^{2}$ Department \\ of Molecular and Integrative Physiology, University of Michigan, Ann Arbor, Michigan, 48109-5622, ${ }^{3}$ Edison Biotechnology Institute and Heritage \\ College of Osteopathic Medicine, Ohio University, Athens, Ohio, 45701, and ${ }^{4}$ Departamento de Fisiologia e Biofísica, Instituto de Ciências \\ Biológicas, Universidade Federal de Minas Gerais, Belo Horizonte, MG Brazil, 31270901
}

Classical studies suggest that growth hormone (GH) secretion is controlled by negative-feedback loops mediated by GH-releasing hormone (GHRH)- or somatostatin-expressing neurons. Catecholamines are known to alter GH secretion and neurons expressing TH are located in several brain areas containing GH-responsive cells. However, whether TH-expressing neurons are required to regulate GH secretion via negative-feedback mechanisms is unknown. In the present study, we showed that between $50 \%$ and $90 \%$ of TH-expressing neurons in the periventricular, paraventricular, and arcuate hypothalamic nuclei and locus ceruleus of mice exhibited STAT5 phosphorylation (pSTAT5) after an acute GH injection. Ablation of GH receptor (GHR) from TH cells or in the entire brain markedly increased GH pulse secretion and body growth in both male and female mice. In contrast, GHR ablation in cells that express the dopamine transporter (DAT) or dopamine $\beta$-hydroxylase (DBH; marker of noradrenergic/adrenergic cells) did not affect body growth. Nevertheless, less than $50 \%$ of TH-expressing neurons in the hypothalamus were found to express DAT. Ablation of GHR in TH cells increased the hypothalamic expression of Ghrh mRNA, although very few GHRH neurons were found to coexpress TH- and GH-induced pSTAT5. In summary, TH neurons that do not express DAT or DBH are required for the autoregulation of GH secretion via a negative-feedback loop. Our findings revealed a critical and previously unidentified group of catecholaminergic interneurons that are apt to sense changes in GH levels and regulate the somatotropic axis in mice.

Key words: catecholamines; dopamine; hypothalamus; neuroendocrinology; neuropeptides; somatotropic axis

Significance Statement

Textbooks indicate until now that the pulsatile pattern of growth hormone (GH) secretion is primarily controlled by GHreleasing hormone and somatostatin neurons. The regulation of GH secretion relies on the ability of these cells to sense changes in circulating GH levels to adjust pituitary GH secretion within a narrow physiological range. However, our study identifies a specific population of tyrosine hydroxylase-expressing neurons that is critical to autoregulate $\mathrm{GH}$ secretion via a negative-feedback loop. The lack of this mechanism in transgenic mice results in aberrant GH secretion and body growth. Since GH plays a key role in cell proliferation, body growth, and metabolism, our findings provide a major advance to understand how the brain regulates the somatotropic axis.

Received Oct. 22, 2019; revised Mar. 30, 2020; accepted Apr. 3, 2020.

Author contributions: F.W., J.A.B.P., W.O.d.S., I.C.F., D.G.-G., and C.F.E. performed research; F.W., D.G.-G., R.E.S., and J.D. analyzed data; F.W., C.F.E., E.O.L., and R.E.S. edited the paper; E.O.L., J.J.K., R.E.S., and J.D. contributed unpublished reagents/analytic tools; J.D. designed research; J.D. wrote the paper.

This work was supported by Fundação de Amparo à Pesquisa do Estado de São Paulo Grants 16/20897-3 to F.W., 16/09679-4 to I.C.F., and 17/02983-2 to J.D.; Fundação de Amparo à Pesquisa do Estado de Minas Gerais Grant CBB-APQ-03308-16 to R.E.S.; National Institutes of Health, National Institute on Aging Grant R01AG059779 to J.J.K. and E.O.L.; and National Institute of Child Health and Human Development Grant R01HD069702 to D.G.-G. and C.F.E. We thank Ana M.P. Campos for technical assistance.

The authors declare no competing financial interests.

Correspondence should be addressed to Jose Donato at jdonato@icb.usp.br.

https://doi.org/10.1523/JNEUROSCI.2531-19.2020

Copyright $\odot 2020$ the authors

\section{Introduction}

Growth hormone $(\mathrm{GH})$ is produced by somatotropic cells of the anterior pituitary gland under the control of different factors secreted by the hypothalamus into the hypophyseal portal system (Steyn et al., 2016). Although numerous neuropeptides, neuromodulators, hormones, and metabolites regulate GH secretion, hypothalamic neurons that express $\mathrm{GH}$-releasing hormone (GHRH) or somatostatin (SST) play a key role controlling the pulsatile pattern of GH secretion in humans and rodents (Steyn et al., 2016). Whereas neuroendocrine SST neurons located in the hypothalamic periventricular (PV) and paraventricular $(\mathrm{PVH})$ nuclei exert an inhibitory effect on $\mathrm{GH}$ secretion, 
hypophysiotropic GHRH neurons in the ventrolateral arcuate nucleus (ARH) stimulate $\mathrm{GH}$ release (Fodor et al., 2006).

The pulsatile pattern of $\mathrm{GH}$ secretion is autoregulated by negative-feedback loops that act in hypothalamic neurons (Nass et al., 2000a) or pituitary gland (Nass et al., 2000b). In addition to these GH-mediated negative-feedback mechanisms, changes in circulating levels of ghrelin (Nass et al., 2008; Xie et al., 2015) or insulin-like growth factor-1 (IGF-1) (Morita et al., 1987; Gahete et al., 2011) also modulate pituitary GH secretion. SST neurons, rather than GHRH cells, likely represent the major GH-negative-feedback node in the brain (Wagner et al., 1998). While $70 \%$ of SST neurons of the PV and PVH express the $\mathrm{GH}$ receptor (GHR) (Burton et al., 1992), $<10 \%$ of GHRH neurons contain Ghr mRNA (Burton et al., 1995). Central administration of $G h r$ mRNA antisense decreases Sst mRNA in the PV, leading to increased GH pulsatility, without affecting Ghrh expression (Pellegrini et al., 1996). However, GHRH neurons are drastically affected by changes in GH levels (Chomczynski et al., 1988; Bertherat et al., 1993; de Gennaro Colonna et al., 1993), indicating that indirect neural circuits detect changes in circulating $\mathrm{GH}$ and regulate GHRH secretion accordingly. Neurons that express SST or neuropeptide Y (NPY) are potential candidates for this indirect regulation since these cells express GHR (Burton et al., 1992; Chan et al., 1996; Kamegai et al., 1996) and exert a regulatory effect on GHRH neurons (Catzeflis et al., 1993; Minami et al., 1998). However, ablation of GHR in ARH neurons that coexpress the agoutirelated protein and NPY causes no changes in GH secretion or body growth (Furigo et al., 2019).

Using the capacity of an acute systemic GH injection to induce the phosphorylation of STAT5 (pSTAT5), we mapped the distribution of $\mathrm{GH}$-responsive cells in the mouse brain (Furigo et al., 2017). We confirmed the presence of GH-responsive neurons in the PV, PVH, and ARH, and further demonstrated that GH can robustly induce pSTAT5 in other brain structures, including the locus ceruleus (LC). LC is the major site responsible for the release of noradrenaline in the forebrain, and LC lesions lead to increased GH secretion (Bluet-Pajot et al., 1992). Additionally, GHRH and SST neurons receive noradrenergic inputs from brainstem neurons (Iqbal et al., 2005). Importantly, $\alpha 2$-adrenergic agonists, such as clonidine, stimulate $\mathrm{GH}$ secretion, whereas agonists of $\alpha 1$ - and $\beta$-adrenergic receptors inhibit GH release (Steyn et al., 2016). Dopaminergic neurons are also located in hypothalamic areas containing $\mathrm{GH}$ responsive cells. Of note, disruption of the D2 dopamine receptor in the CNS reduces GH secretion and hypothalamic Ghrh expression causing dwarfism (Díaz-Torga et al., 2002; Noaín et al., 2013). Thus, catecholaminergic neurons, including noradrenergic and dopaminergic cells, seem to be implicated in the hypothalamic control of GH secretion. However, it is still unknown whether catecholaminergic neurons are responsive to $\mathrm{GH}$ and whether ablation of GHR in these cells affects the pulsatile GH secretion and consequently body growth. Therefore, the objective of the present study was to investigate whether different groups of catecholaminergic neurons are required to regulate $\mathrm{GH}$ secretion via negative-feedback mechanisms. For this purpose, we first identified catecholaminergic neurons that are responsive to GH. Then, we used different mouse models to study the consequences of the genetic ablation of GHR in catecholaminergic, dopaminergic, or noradrenergic/adrenergic cells, and in the entire brain.

\section{Materials and Methods}

Mice

Adult (12-week-old) C57BL/6 WT male mice were used to identify catecholaminergic neurons that are responsive to GH. To induce the ablation of GHR in specific subpopulations of catecholaminergic neurons, mice carrying loxP-flanked Ghr alleles (List et al., 2013) were bred with the dopamine transporter (DAT)-IRES-Cre mouse (stock \#006660, JAX mice), dopamine $\beta$-hydroxylase (DBH)-Cre mouse (Parlato et al., 2007) or TH-Cre mouse (stock \#008601, JAX mice). Inactivation of GHR in the entire brain was achieved by breeding mice carrying loxP-flanked Ghr alleles with the Nestin-Cre mouse (stock \#003771; JAX mice). The resulting heterozygous mice for the Ghrlox mutation and positive for Cre allele were further crossed with $G h r^{\text {flox } f l o x}$ mice, generating $G h r^{\text {flox/flox }}$ mice carrying the Cre gene (DAT GHR KO, DBH GHR KO, TH GHR $\mathrm{KO}$, or BRAIN GHR KO mice). Control groups were composed of $G h r^{f l o x / f l o x}$ littermates that were negative for the Cre gene. To visualize DAT and SST neurons, DAT-IRES-Cre and SST-IRES-Cre (stock \#018973, JAX mice) mice were crossed with the LoxP-Stop-LoxP 

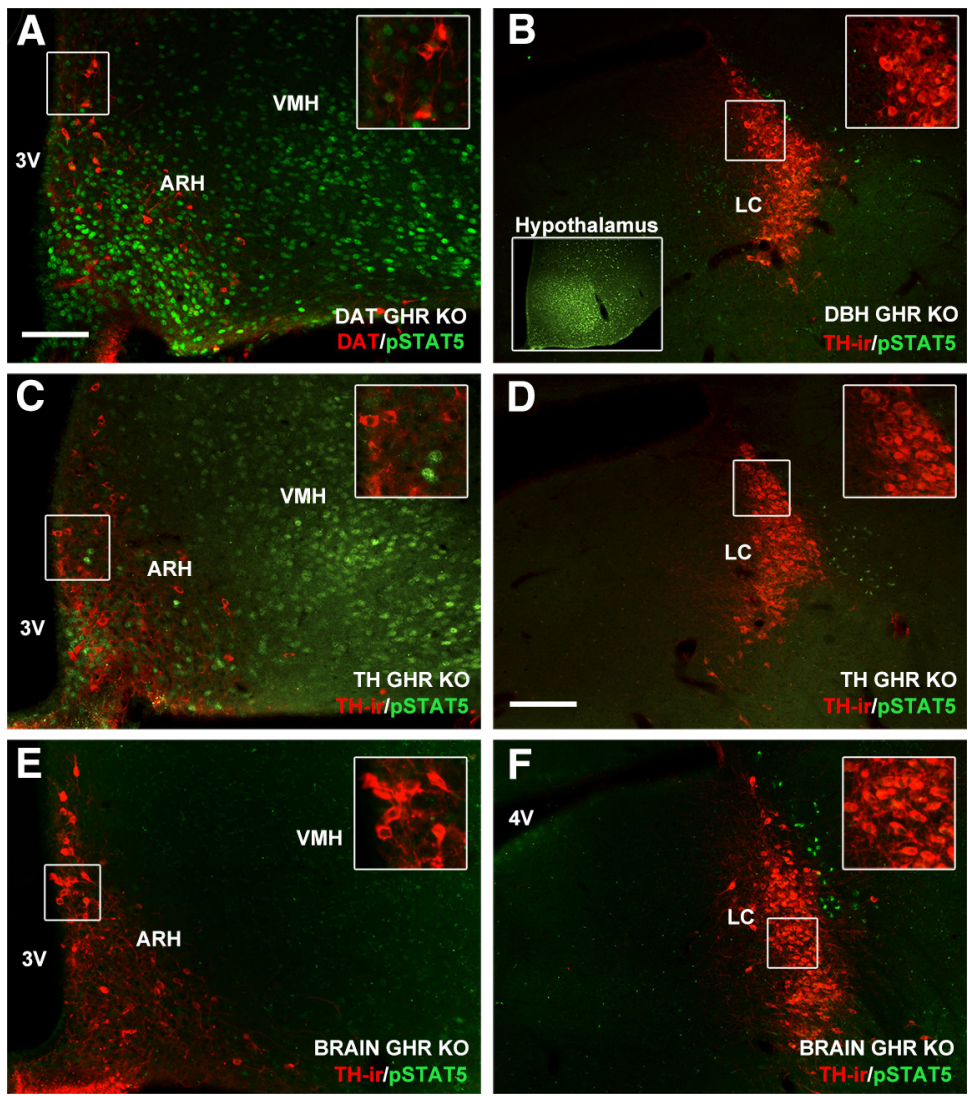

Figure 2. Ablation of GHR in subpopulations of catecholaminergic neurons or in the entire brain. $A$, Epifluorescence photomicrograph demonstrating the ablation of GHR in DAT-expressing cells (visualized by the red tdTomato reporter protein). GHinduced PSTAT5 (green) was only found in DAT-negative cells. $\boldsymbol{B}-\boldsymbol{F}$, Epifluorescence photomicrographs demonstrating the ablation of GHR in TH-ir (red) neurons in the DBH GHR KO $(\boldsymbol{B})$, TH GHR KO $(\boldsymbol{C}, \boldsymbol{D})$, and BRAIN GHR KO $(\boldsymbol{E}, \boldsymbol{F})$ male mice. Insets, Higher-magnification photomicrographs of the selected area or of the hypothalamus $(B)$. $3 \mathrm{~V}$, Third ventricle; $4 \mathrm{~V}$, fourth ventricle; VMH, ventromedial nucleus. Scale bars: $\boldsymbol{A}-\boldsymbol{C}, \boldsymbol{E}, 100 \mu \mathrm{m} ; \boldsymbol{D}, \boldsymbol{F}, 200 \mu \mathrm{m}$.

tdTomato-reporter mouse (stock \#007909, The Jackson Laboratory). GHRH neurons were visualized using young adult $\mathrm{Ghrh}^{\mathrm{Cre} /-}$ / eGFP-L10a mice (Rupp et al., 2018), kindly provided by Martin Myers (University of Michigan; now available at JAX mice, stock \#031096). The mutations were confirmed by genotyping the DNA previously extracted from the tail tip of all mice using a commercially available kit (REDExtract-N-Amp Tissue PCR Kit, Sigma Millipore). Mice were produced and maintained in standard conditions of light (12 h light/ dark cycle) receiving a regular rodent chow diet. All experiments were conducted in compliance with National Institutes of Health's Guide for the care and use of laboratory animals and were previously approved by the Ethics Committee on the Use of Animals of the Institute of Biomedical Sciences at the University of São Paulo (Protocol 73/2017).

\section{Detection of GH-responsive neurons}

To visualize GH-responsive neurons, adult male mice received an acute intraperitoneal injection of porcine pituitary GH $[20 \mu \mathrm{g} / \mathrm{g}$, from A.F. Parlow, National Institute of Diabetes and Digestive and Kidney Diseases-National Hormone and Pituitary Program (NIDDK-NHPP)]. $\mathrm{Ghrh}^{\mathrm{Cre} /-}$ /eGFP-L10a mice received an acute intraperitoneal injection of mouse recombinant GH (20 $\mu \mathrm{g} / \mathrm{g}$; NIDDK-NHPP). PBS-injected mice were used as controls. Ninety minutes after the injections, mice were deeply anesthetized with isoflurane and perfused transcardially with saline, followed by a $10 \%$ buffered formalin solution. Brains were collected and postfixed in the same fixative for $60 \mathrm{~min}$ and cryoprotected overnight at $4^{\circ} \mathrm{C}$ in $0.1 \mathrm{M}$ PBS containing $20 \%$ sucrose. Brains were cut in $30-\mu \mathrm{m}$-thick sections using a freezing microtome. Brain slices were rinsed in $0.02 \mathrm{M}$ potassium PBS, $\mathrm{pH} 7.4$ (KPBS), followed by pretreatment in water solution containing $1 \%$ hydrogen peroxide and $1 \%$ sodium hydroxide for $20 \mathrm{~min}$. After rinsing in KPBS, sections were incubated in $0.3 \%$ glycine and $0.03 \%$ lauryl sulfate for $10 \mathrm{~min}$ each. Next, slices were blocked in 3\% normal donkey serum for $1 \mathrm{~h}$, followed by incubation in anti-pSTAT5 ${ }^{\text {Tyr694 }}$ primary antibody (Cell Signaling Technology, catalog \#9351, 1:1000; RRID:AB_2315225) for $40 \mathrm{~h}$. After incubation in the primary antibody, slices were submitted to fluorescence reaction or immunoperoxidase staining according to the experiment. For the immunofluorescence reactions, sections were rinsed in KPBS and incubated for $90 \mathrm{~min}$ in AlexaFluor-488-conjugated secondary antibody (1:500, Jackson ImmunoResearch Laboratories). For the immunoperoxidase staining, sections were incubated for $1 \mathrm{~h}$ in biotin-conjugated secondary antibody (1:1000, Jackson ImmunoResearch Laboratories) and next for $1 \mathrm{~h}$ with an avidinbiotin complex (1:500, Vector Labs). The peroxidase reaction was performed using $0.05 \%$ $\mathrm{DAB}$ and $0.01 \%$ hydrogen peroxide. TH immunoreactivity (TH-ir) was detected in brain sections incubated overnight in anti-TH primary antibody (catalog \#MO22941-100, 1:1000; RRID:AB_1624244), followed by incubation for $90 \mathrm{~min}$ in AlexaFluor-594- or AlexaFluor-405-conjugated secondary antibodies (1:500 and 1:250, respectively; Jackson ImmunoResearch Laboratories). To colocalize GHRH and TH cells in the ARH, brain sections of $\mathrm{Ghrh}^{\mathrm{Cre} / /} / \mathrm{eGFP}-\mathrm{L} 10 \mathrm{a}$ mice were incubated overnight at $4^{\circ} \mathrm{C}$ in either sheep anti-TH (Millipore, catalog \#AB1542, 1:2000; RRID:AB_90755) or chicken anti-GFP (Aves Labs, catalog \#GFP-1020, 1:10000; RRID: AB_10000240) primary antibodies. Subsequently, sections were rinsed and incubated in AlexaFluor-594-conjugated anti-sheep IgG and AlexaFluor-488-conjugated anti-chicken IgG antibodies (1:500, Invitrogen) for $1.5 \mathrm{~h}$. All sections were mounted onto gelatin-coated slides, and the slides were covered with Fluoromount G mounting medium (Electron Microscopic Sciences). Photomicrographs were acquired with an Axio Imager A1 (Carl Zeiss) or Axio Imager M2 (Carl Zeiss) microscopes. The number and percentage of single-, double-, or triple-labeled cells in the areas of interest were determined in one or two rostrocaudal levels of the PV (bregma: -0.34 $\mathrm{mm}$ ), PVH (bregma: -0.70 and $-0.82 \mathrm{~mm}$ ), ARH (bregma: -1.34 and $-1.58 \mathrm{~mm}$ ), substantia nigra pars compacta (SNpc; bregma: $-2.92 \mathrm{~mm}$ ), and LC (bregma: $-5.40 \mathrm{~mm}$ ).

\section{Dual-label ISH and immunohistochemistry}

The Ghrh DNA template was generated from mouse hypothalamic RNA by PCR amplification of a $402 \mathrm{bp}$ region, starting at position $105 \mathrm{nt}$ (NM_010285). The antisense radio-labeled riboprobe was generated by in vitro transcription using T7 RNA polymerase (Promega). Dual-label ISH and immunohistochemistry were performed to confirm the distribution of Ghrh transcript in GHRH-eGFP ${ }^{+}$neurons. Free-floating sections from adult GHRH-eGFP female mice $(n=3)$ were treated with $0.1 \%$ sodium borohydride for $15 \mathrm{~min}$ and with $0.25 \%$ acetic anhydride in DEPC-treated $0.1 \mathrm{M}$ triethanolamine, $\mathrm{pH} 8.0$, for $10 \mathrm{~min}$. Sections were incubated overnight at $50^{\circ} \mathrm{C}$ in the hybridization solution containing the ${ }^{35}$ S-labeled Ghrh riboprobe. Subsequently, sections were treated with RNase A for 30 min and submitted to stringency washes. Sections were blocked in 3\% BSA, then incubated with a primary chicken anti-GFP antibody (1:10000) overnight at $4^{\circ} \mathrm{C}$. Sections were incubated for $1 \mathrm{~h}$ in donkey biotinylated anti-chicken IgG (1:1000, 
20 week-old males
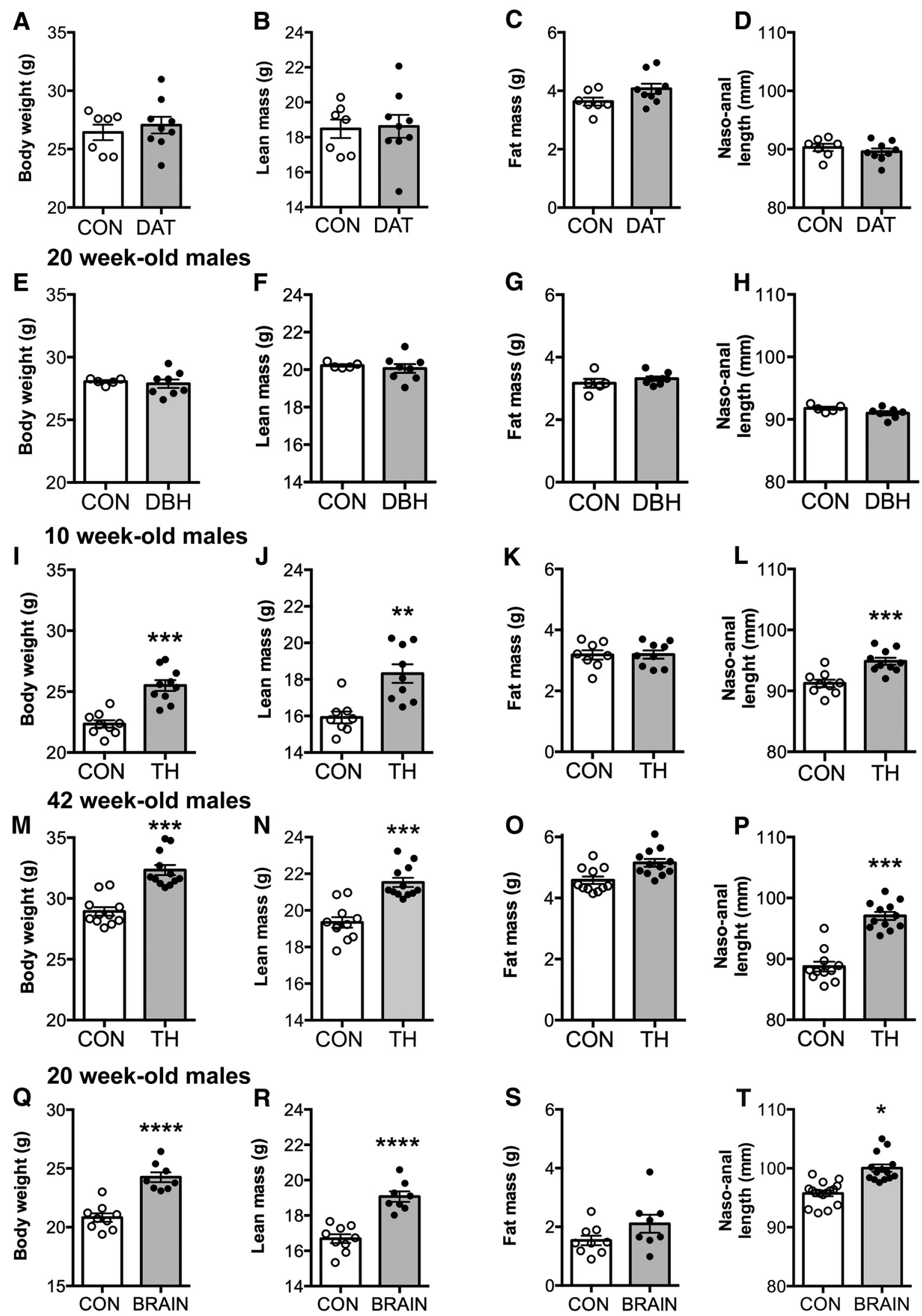

Figure 3. Consequences of GHR ablation in different subpopulations of catecholaminergic neurons or in the entire brain of male mice. $\boldsymbol{A}-\boldsymbol{D}$, Body weight $(\boldsymbol{A})$, lean body mass $(\boldsymbol{B})$, body fat mass $(\boldsymbol{C}$, and naso-anal length $(\boldsymbol{D})$ in 20-week-old control and DAT GHR K0 mice $(n=6-9)$. $\boldsymbol{E}-\boldsymbol{H}$, Body weight $(\boldsymbol{E})$, lean body mass $(\boldsymbol{F})$, body fat mass $(\boldsymbol{G})$, and naso-anal length $(\boldsymbol{H})$ in 20 week-old control and DBH GHR KO mice $(n=5-8)$. I-L, Body weight $(\boldsymbol{l})$, lean body mass $(\boldsymbol{J})$, body fat mass $(\boldsymbol{K})$, and naso-anal length $(\boldsymbol{L})$ in 10 -week-old control and TH GHR K0 mice $(n=9$ or 
20 week-old males

A

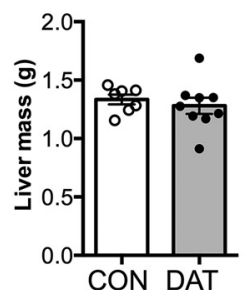

B

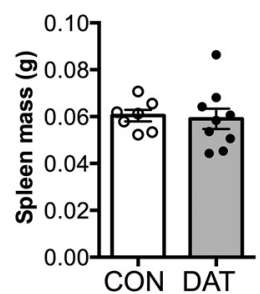

20 week-old males

E

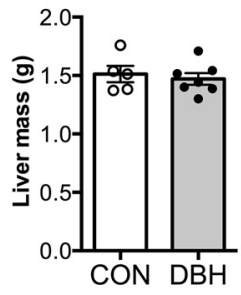

$\mathbf{F}$

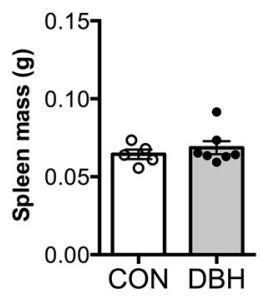

42 week-old males

I

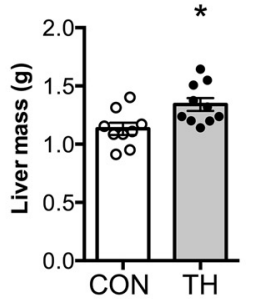

J

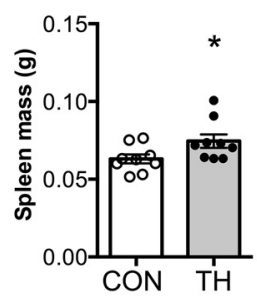

20 week-old males

M

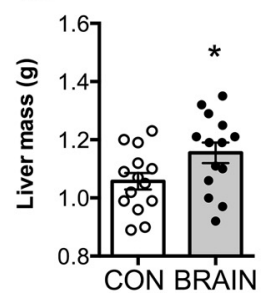

C

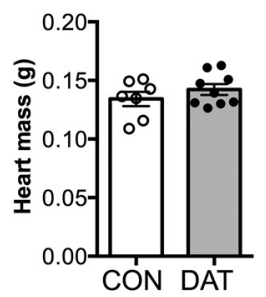

G

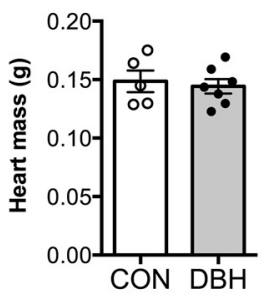

K

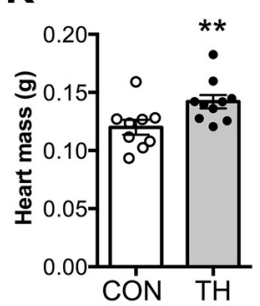

0

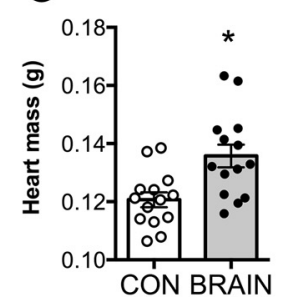

L

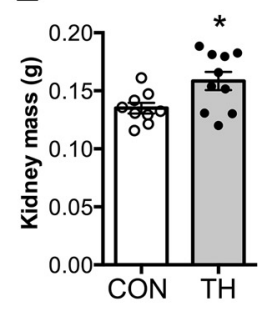

D

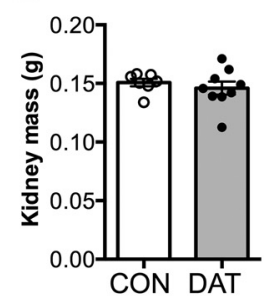

H

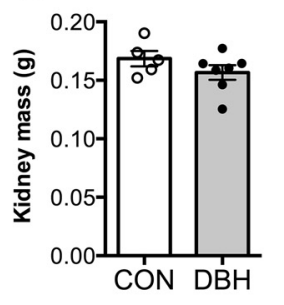

$\mathbf{P}$

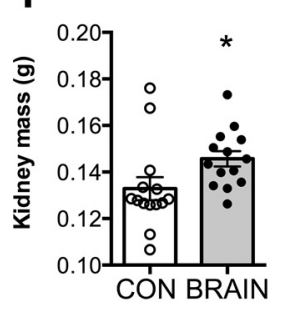

Figure 4. Consequences of GHR ablation in different subpopulations of catecholaminergic neurons or in the entire brain of male mice. $\boldsymbol{A}-\boldsymbol{D}$, Liver $(\boldsymbol{A})$, spleen $(\boldsymbol{B})$, heart $(\boldsymbol{C})$, and kidney $(\boldsymbol{D})$ masses in 20-week-old DAT GHR KO mice $(n=7-9)$. $\boldsymbol{E}$ - $\boldsymbol{H}$, Liver $(\boldsymbol{E})$, spleen $(\boldsymbol{F})$, heart $(\boldsymbol{G})$, and kidney $(\boldsymbol{H})$ masses in 20-week-old DBH GHR KO mice $(n=5-7)$. I-L, Liver $(\boldsymbol{I})$, spleen $(\boldsymbol{J})$, heart $(\boldsymbol{K})$, and kidney $(\boldsymbol{L})$ masses in 42-week-old TH GHR KO mice $(n=9$ or 10$)$. $\boldsymbol{M}$ - $\boldsymbol{P}$, Liver $(\boldsymbol{M})$, spleen $(\boldsymbol{N})$, heart $(\boldsymbol{0})$, and kidney $(\boldsymbol{P})$ in 20-week-old BRAIN GHR KO mice $(n=14) .{ }^{*} p<0.05 ;{ }^{* *} p<0.01$ versus control group; two-tailed Student's $t$ test. Data are mean \pm SEM.

Jackson ImmunoResearch Laboratories), followed by $1 \mathrm{~h}$ incubation with avidin-biotin complex (1:500, Vector Labs). The detection reaction was performed using $0.05 \% \mathrm{DAB}$ and $0.01 \%$ hydrogen peroxide. Sections were mounted onto SuperFrost plus slides, dipped in NTB-2 autoradiographic emulsion, and stored in light-protected boxes at $4^{\circ} \mathrm{C}$ for 3 weeks. Slides were developed and mounted with DPX medium.

10). $\boldsymbol{M}-\boldsymbol{P}$, Body weight $(\boldsymbol{M})$, lean body mass $(\boldsymbol{M})$, body fat mass $(\boldsymbol{O})$, and naso-anal length (P) in 42-week-old control and TH GHR KO mice $(n=11)$. $\mathbf{Q}-\mathbf{T}$, Body weight (Q), lean body mass $(\boldsymbol{R})$, body fat mass $(\boldsymbol{S})$, and naso-anal length $(\boldsymbol{T})$ in 20-week-old control and BRAIN GHR K0 mice $\left(n=8\right.$ or 9 ). ${ }^{*} p<0.05 ;{ }^{* *} p<0.01 ;{ }^{* * *} p<0.001 ;{ }^{* * *} p<0.0001$ versus control group; two-tailed Student's $t$ test. Data are mean \pm SEM.

Evaluation of somatic growth

To determine possible changes in somatic growth, different groups of male and female mice at $\sim 10,20$, or 42 weeks of age were weighed, and their body fat and lean masses were measured by time-domain nuclear magnetic resonance using the LF50 body composition mice analyzer (Bruker). Naso-anal length and the masses of the liver, spleen, heart, kidney, perigonadal adipose tissue, testicle, brain, and gastrocnemius muscle were also determined. Serum IGF-1 concentration was determined by ELISA (\#MG100; R\&D Systems).

\section{Evaluation of pulsatile GH secretion}

To minimize stress interference during the blood collection, disposable cardboard tubes were placed inside the cages, and each mouse was handled daily in these cardboard tubes. This procedure was performed for $30 \mathrm{~d}$ before the experiment to acclimate to the procedure of tail-tip blood sampling. Experiments started at the beginning of the light cycle $(7: 00 \mathrm{~h})$, and 36 sequential tail-tip blood samples of $5 \mu \mathrm{l}$ were collected from each mouse at $10 \mathrm{~min}$ intervals (Steyn et al., 2011). Each animal was sampled on a single day, over a $6 \mathrm{~h}$ period. Immediately before the first sample collection, a small portion of the tail tip $(1 \mathrm{~mm})$ was cut with a surgical blade to allow the collection of small drops of blood. During the whole period of the experiment, mice were allowed to move freely in their home cage with ad libitum access to food and water. For each blood collection, mice were placed inside the cardboard tube and quickly held by the base of the tail. Using a $10 \mu$ l pipette, a $5 \mu \mathrm{l}$ sample of whole blood was collected and transferred to $105 \mu \mathrm{l}$ of PBS with 0.05\% Tween-20 (PBS-T). After each blood collection, a fingertip pressure was gently applied to the tail tip to stop bleeding. This procedure practically causes no stress to the animals; otherwise, stress-induced tail vasoconstriction due to sympathetic activation would prevent any detection of hormonal pulsatile secretion. Samples were immediately placed on dry ice and stored at $-80^{\circ} \mathrm{C}$ for later analysis. We completed the assessment of pulsatile GH secretion in both 8- and 18-week-old male mice.

For the assessment of $\mathrm{GH}$ levels in the whole blood, we used a GH-sensitive sandwich ELISA adapted from a protocol published by Steyn et al. (2011). A 96-well high-binding plate (9018, Corning) was coated with $50 \mu \mathrm{l}$ of monkey anti-rat GH antibody (rGH-IC-1, AFP411S, NIDDK-NHPP; RRID:AB_2665564) diluted in PBS at 1:50 000 overnight at $4^{\circ} \mathrm{C}$. After decanting the coating antibody, wells were incubated with $200 \mu$ of blocking buffer (5\% skim milk powder in PBS-T) for $2 \mathrm{~h}$ at room temperature. The standard curve consisted of a twofold serial dilution of mouse recombinant $\mathrm{GH}$ (mGH reference preparation, AFP-10783B, NIDDK-NHPP) in $0.2 \%$ BSA PBS-T. The wells were incubated with $50 \mu \mathrm{l}$ of samples at a 1:20 dilution for $24 \mathrm{~h}$ at room temperature. The plate was washed in PBS-T, and the wells were incubated with $50 \mu \mathrm{l}$ of rabbit anti-rat GH antibody (AFP5672099, NIDDKNHPP; RRID:AB_2721132) diluted in blocking buffer at 1:100,000 for $24 \mathrm{~h}$ at $4^{\circ} \mathrm{C}$. After washing in PBS-T, wells were incubated with $50 \mu \mathrm{l}$ of HRP-conjugated goat anti-rabbit IgG antibody (A9169-2 ml, Sigma Millipore) diluted in 50\% PBS, 50\% blocking buffer at 1:30,000 for 
$90 \mathrm{~min}$ at room temperature. After a final wash in PBS-T, wells were incubated with $100 \mu \mathrm{l}$ of $2 \mathrm{mg} / \mathrm{ml}$ o-phenylenediamine dihydrochloride (P1526, Sigma Millipore) in citrate-phosphate buffer, $\mathrm{pH}$ 5.0, containing $0.02 \%$ hydrogen peroxide for $45 \mathrm{~min}$ at room temperature. The reaction was stopped with $50 \mu \mathrm{l}$ of $3 \mathrm{M} \mathrm{HCl}$. The absorbance was determined at $490 \mathrm{~nm}$ with a microplate reader (Epoch, Biotek), and the wavelength of $650 \mathrm{~nm}$ was used for background correction. The standard curve ranged from $0.03-15 \mathrm{ng} /$ $\mathrm{ml}$, and the concentration of $\mathrm{GH}$ was calculated by interpolating the optical density of the samples against a nonlinear regression of the standard curve. The lower limit of detection was $0.04 \mathrm{ng} / \mathrm{ml}$, and the intra-assay and interassay coefficients of variation were $2.6 \%$ and $9.7 \%$, respectively. GH pulses were detected using the DynPeak pulse detection algorithm (Vidal et al., 2012). Default parameters of the algorithm were used, with the exception of the global relative threshold increased from $20 \%$ to $50 \%$ to reduce probability of detecting false-positive pulses. The number of GH pulses was calculated for the period of $6 \mathrm{~h}$. The amplitude of each pulse was defined as the difference between peak value and its nadir, and the average levels of the detected pulses were considered for the statistical analysis of pulse amplitude. Mean $\mathrm{GH}$ was calculated by averaging all GH values from each mouse.

\section{$q R T-P C R$}

Total RNA from the whole hypothalamus was extracted with TRIzol (Invitrogen). Assessment of RNA quantity and quality was performed with an Epoch Microplate Spectrophotometer (Biotek). Total RNA was incubated in DNase I RNase-free (Roche Applied Science). Reverse transcription was performed with $2 \mu \mathrm{g}$ of total RNA with SuperScript II Reverse Transcriptase (Invitrogen) and random primers $\mathrm{p}(\mathrm{dN}) 6$ (Roche Applied Science). Real-time PCR was performed using the $7500 \mathrm{TM}$ RealTime PCR System (Applied Biosystems) and Power SYBR Green or TaqMan PCR Master Mixes (Applied Biosystems). Relative quantification of mRNA was calculated by $2^{-\Delta \Delta \mathrm{Ct}}$. Data were normalized to the geometric average of Actb, Gapdh, and Ppia and reported as fold changes compared with values obtained from the control group (set at 1.0). The following primers were used: Actb (forward: gctccggcatgtgcaaag; reverse: catcacaccctggtgccta), Gapdh (forward: gggtcccagcttaggttcat; reverse: tacggccaaatccgttcaca), Ghr (forward: atcaatccaagcctggggac; reverse: acagctga atagatcctgggg), Ghrh (forward: tatgcccggaaagtgatccag; reverse: atccttgggaatccctgcaaga), Ppia (forward: tatctgcactgccaagactgagt; reverse: cttc ttgctggtcttgccattcc), Sst (forward: ctgtcctgccgtctccagt; reverse: ctgcagaaactgacggagtct) and Th (TaqMan assay; Mm00447557_m1; Thermo Fisher Scientific).

\section{Statistical analysis}

Data were analyzed by the unpaired two-tailed Student's $t$ test (two groups) or one-way ANOVA (three groups), followed by Bonferroni's multiple comparisons test. Statistical analyses were performed using the

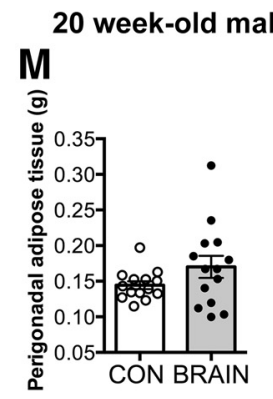

B C
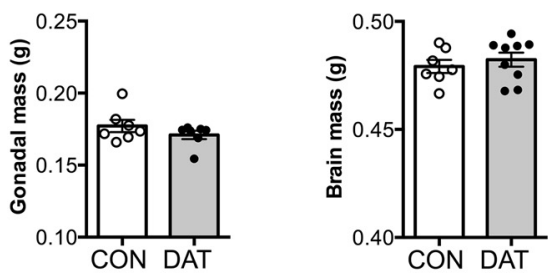

D

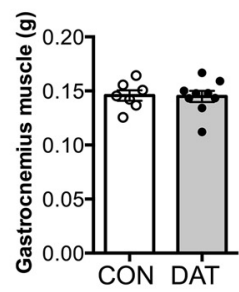

G

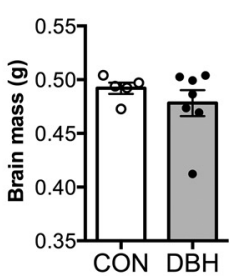

H

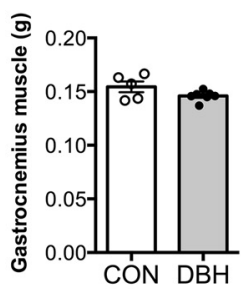

K

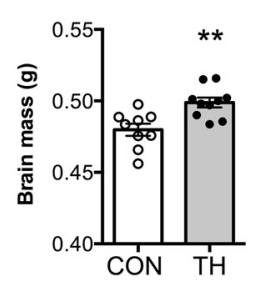

$\mathbf{L}$

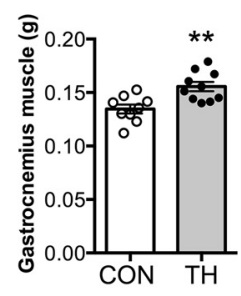

$\mathbf{N}$
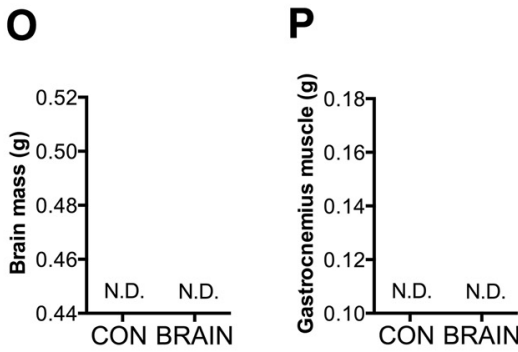

Figure 5. Consequences of GHR ablation in different subpopulations of catecholaminergic neurons or in the entire brain of male mice. $\boldsymbol{A}-\boldsymbol{D}$, Perigonadal adipose tissue $(\boldsymbol{A})$, gonadal $(\boldsymbol{B})$, brain $(\boldsymbol{C})$, and gastrocnemius muscle $(\boldsymbol{D})$ masses in 20-week-old DAT GHR KO mice $(n=7-9)$. $\boldsymbol{E}-\boldsymbol{H}$, Perigonadal adipose tissue $(\boldsymbol{E})$, gonadal $(\boldsymbol{F})$, brain $(\boldsymbol{G})$, and gastrocnemius muscle $(\boldsymbol{H})$ masses in 20-week-old DBH GHR KO mice $(n=5-7)$. $\boldsymbol{I}-\boldsymbol{L}$, Perigonadal adipose tissue $(\boldsymbol{I})$, gonadal $(\boldsymbol{J})$, brain $(\boldsymbol{K})$, and gastrocnemius muscle $(\boldsymbol{L})$ masses in 42-week-old TH GHR KO mice $(n=9$ or 10$)$. $\boldsymbol{M}$-P, Perigonadal adipose tissue $(\boldsymbol{M})$, gonadal $(\boldsymbol{N})$, brain $(\boldsymbol{O})$, and gastrocnemius muscle $(\boldsymbol{P})$ in 20-week-old BRAIN GHR KO mice $(n=14) .{ }^{* *} p<0.01$ versus control group; two-tailed Student's $t$ test. N.D., Not determined. Data are mean \pm SEM.

GraphPad Prism software. We considered $p$ values $<0.05$ to be statistically significant. All results are expressed as mean \pm SEM.

\section{Results}

\section{Distribution of catecholaminergic neurons that are} responsive to $\mathrm{GH}$ in the mouse brain

$\mathrm{GH}$-responsive neurons are abundantly found in numerous brain regions that contain catecholaminergic neurons, including the PV, PVH, and ARH in the hypothalamus and the LC in the pons (Furigo et al., 2017). To determine whether catecholaminergic neurons are directly responsive to $\mathrm{GH}, \mathrm{C} 57 \mathrm{BL} / 6$ male mice received an acute $\mathrm{GH}$ injection and analysis of colocalization 
10 week-old females
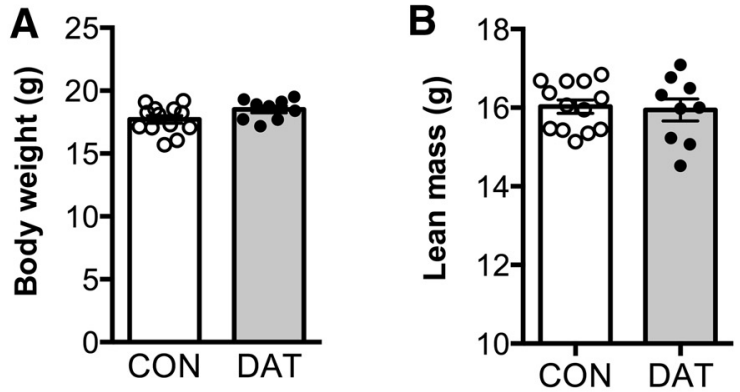

10 week-old females
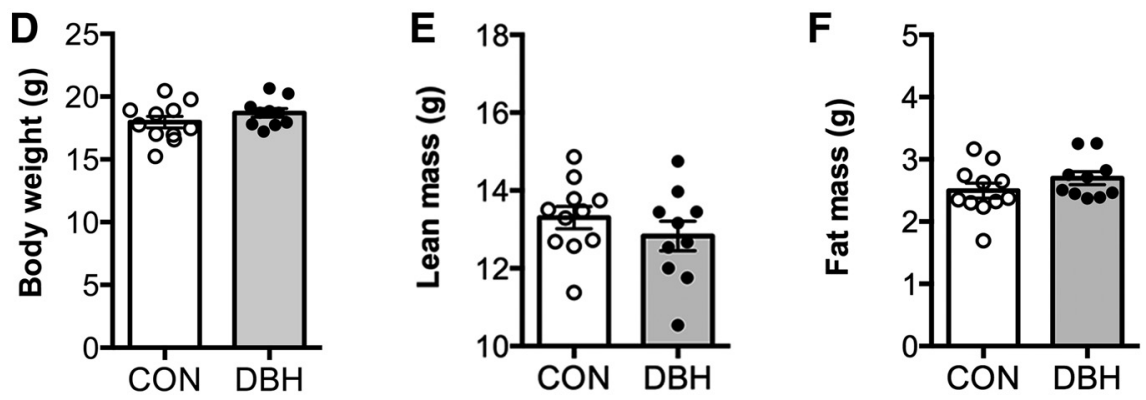

10 week-old females
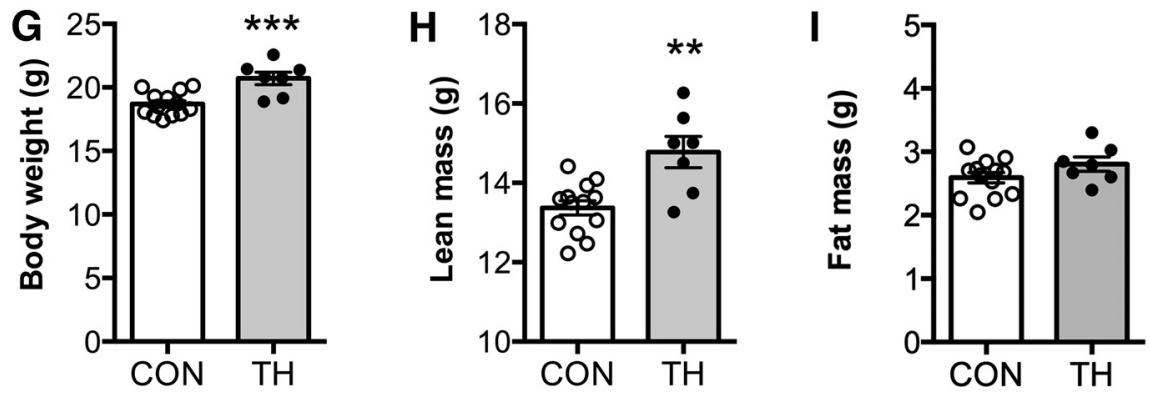

10 week-old females
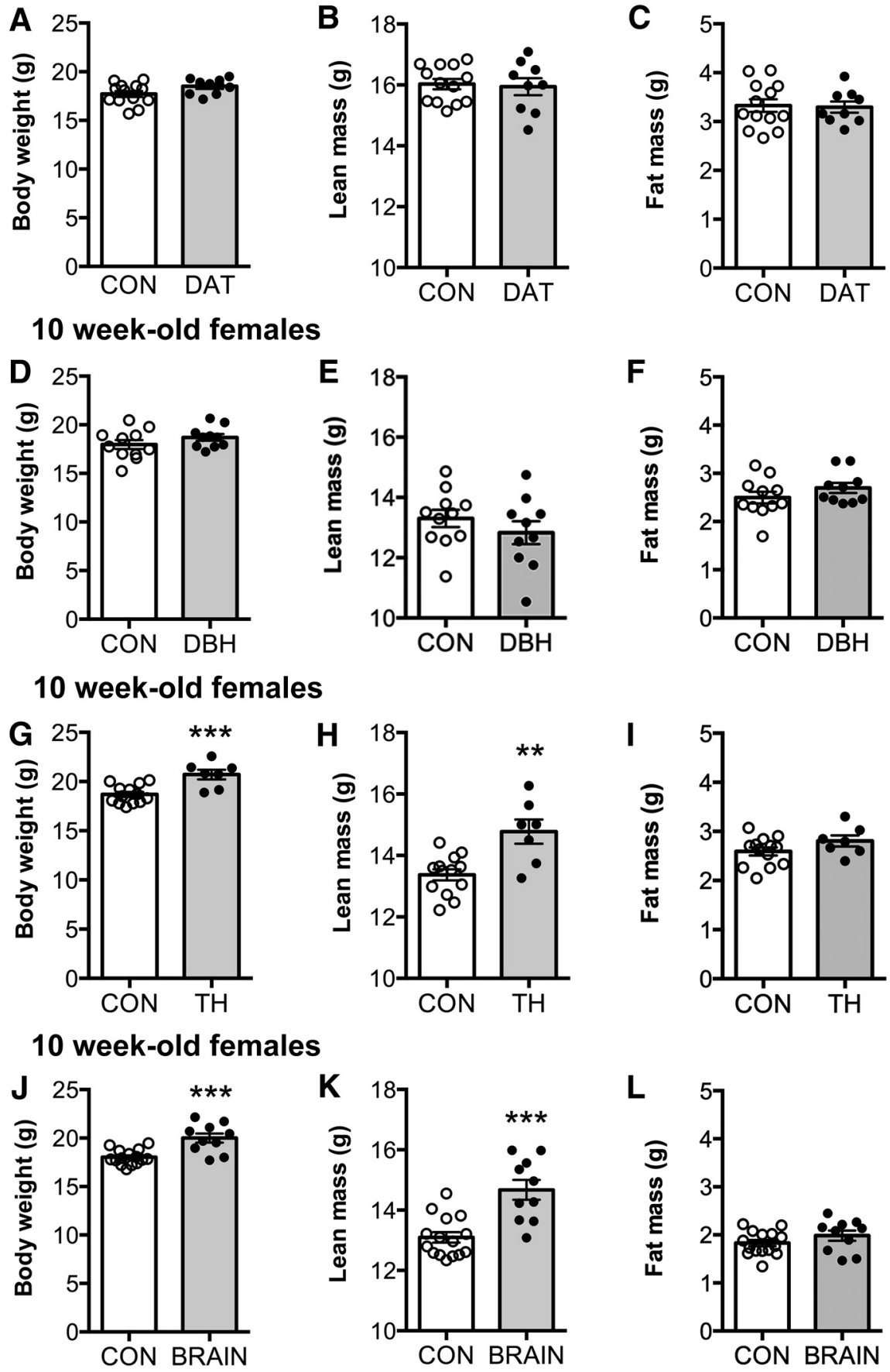

hypothalamus, ventral tegmental area, $\mathrm{C} 1$ and A1 groups in the ventrolateral medulla, and in the nucleus of the solitary tract. PBS-injected mice showed a very small number of pSTAT5-positive cells in the brain and virtually no colocalization with TH neurons (Fig. 1E,F). Thus, several subpopulations of catecholaminergic neurons are responsive to $\mathrm{GH}$.

\section{Cell-specific ablation of GHR in} different types of catecholaminergic neurons

The evidence of functional GHR in catecholaminergic neurons suggests that these cells are apt to sense circulating $\mathrm{GH}$ levels and consequently regulate pituitary GH secretion via negative-feedback loops. To investigate the role of $\mathrm{GH}$ action on catecholaminergic neurons to regulate $\mathrm{GH}$ secretion and consequently somatic growth, we generated mice carrying cell-specific ablations of GHR in different types of catecholaminergic neurons. Since TH is a shared marker of all catecholaminergic cells, we used TH-Cre mice to induce deletion of GHR in all dopaminergic and noradrenergic/adrenergic cells (TH GHR KO mice). To target specifically dopaminergic cells, DAT-IRES-Cre mice were used to ablate GHR in cells that express the dopamine transporter (DAT GHR KO mice). GHR deletion only in noradrenergic and adrenergic cells was achieved using the DBH-Cre mouse (DBH GHR KO mice). Finally, NestinCre mouse was used to induce GHR ablation in the entire brain (BRAIN GHR $\mathrm{KO}$ mice). To confirm the cell-specific deletion in these mouse models, we colocalized GH-induced pSTAT5 with markers of each subpopulation of catecholaminergic neurons (Fig. 2). GH injection in DAT GHR $\mathrm{KO}$ mice induced pSTAT5 in a large number of cells in the hypothalamus (Fig. 2A) and brainstem, as expected. However, using tdTomato reporter protein as a marker of DAT cells, we observed that virtually no DAT cell in the hypothalamus colocalized with $\mathrm{GH}$-induced pSTAT5 in DAT GHR KO mice (Fig. 2A). As shown in WT mice, $95 \pm 2 \%$ of $\mathrm{TH}$ positive noradrenergic neurons in the LC exhibited pSTAT5 after GH injec-

between $\mathrm{GH}$-induced pSTAT5 and $\mathrm{TH}$-ir was performed in brain sections. We observed that $61 \pm 8 \%$ of $\mathrm{TH}$-immunoreactive (TH-ir) neurons in the PV (Fig. 1A), $69 \pm 8 \%$ in the PVH (Fig. 1B), $53 \pm 5 \%$ in the ARH (Fig. 1C), and $86 \pm 3 \%$ in the LC (Fig. 1D) expressed pSTAT5 after GH injection. Some colocalizations were found in other subpopulations of catecholaminergic neurons, including those located in the dorsomedial nucleus of the tion in DAT GHR KO mice, demonstrating that the target deletion only affected dopaminergic cells. In DBH GHR KO mice, a large number of pSTAT5 cells were observed in the hypothalamus (Fig. 2B, inset), whereas noradrenergic neurons of the LC no longer expressed $\mathrm{GH}$-induced pSTAT5 (Fig. 2B). GH injection in TH GHR KO mice was unable to induce pSTAT5 in 


\section{8 weeks of age}

A
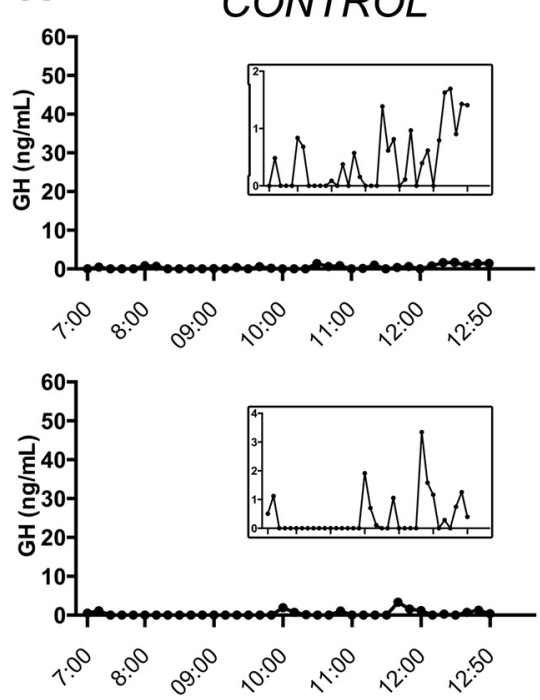

D
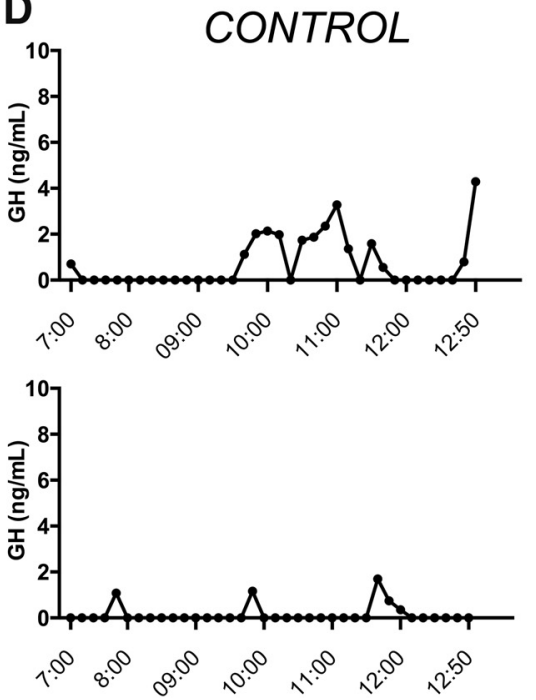

B
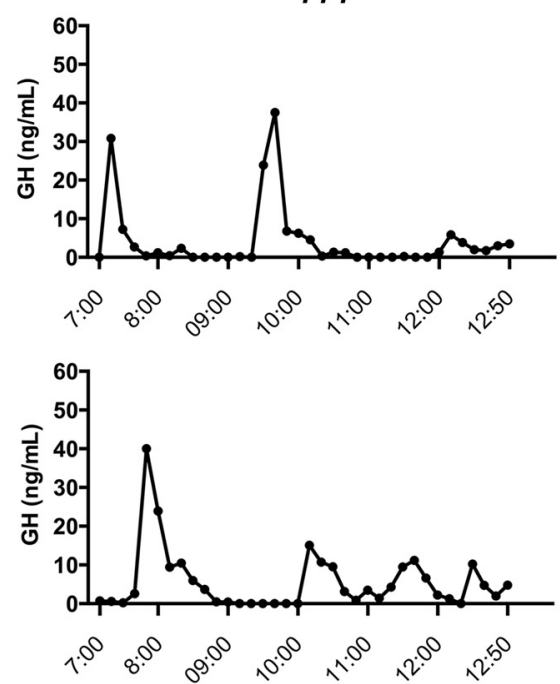

18 weeks of age

E
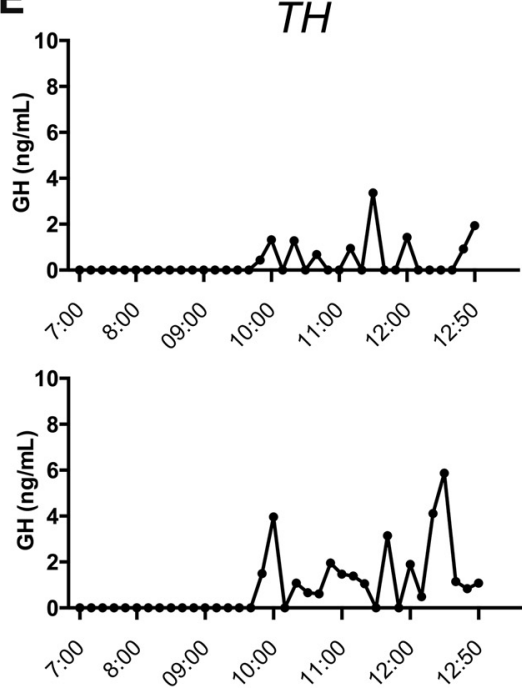

C

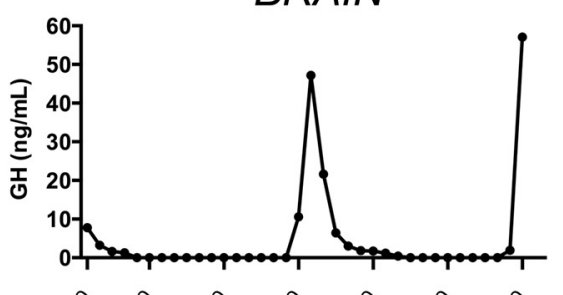

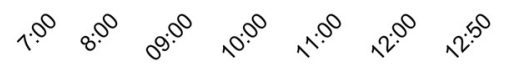

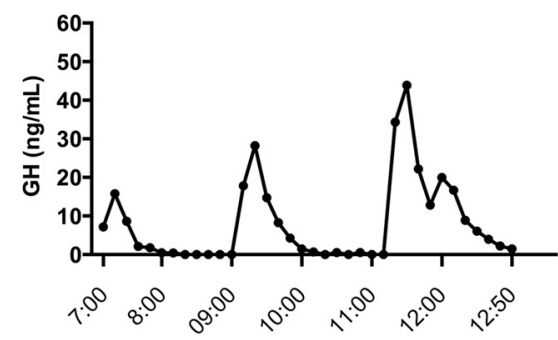

$\mathbf{F}$
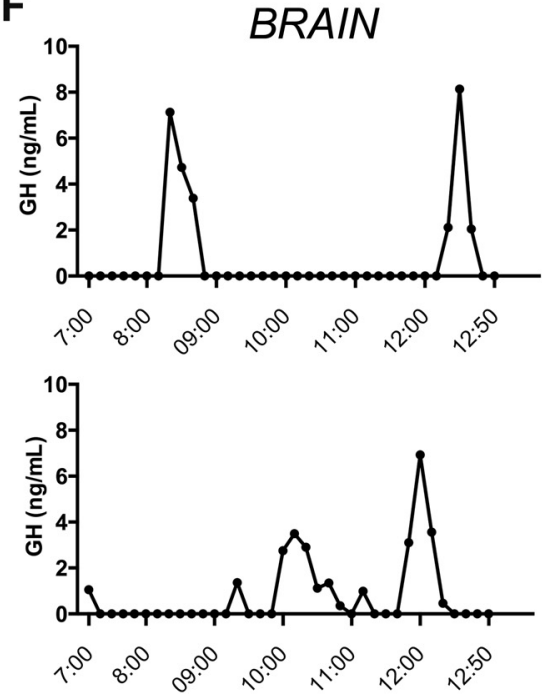

Figure 7. Pulsatile pattern of GH secretion. $\boldsymbol{A}-\boldsymbol{C}$, Representative examples of the pulsatile pattern of GH secretion in 8-week-old control (A), TH GHR KO (B), and BRAIN GHR KO (C) male mice. Since the $y$-axis scale has been standardized in all representative cases shown, the insets represent the pulsatile pattern of $G H$ secretion in the control group on a reduced $y$ axis. $\mathbf{D}-\boldsymbol{F}$, Representative examples of the pulsatile pattern of GH secretion in 18-week-old control (D), TH GHR KO (E), and BRAIN GHR KO (F) male mice. The pulsatile pattern of GH secretion was determined by 36 serial blood collections in each mouse at 10 min intervals during the first $6 \mathrm{~h}$ of the light phase.

TH-ir cells of the hypothalamus (Fig. 2C) and LC (Fig. 2D), whereas a normal distribution of pSTAT5 was observed in brain areas that do not contain TH neurons, such as the ventromedial nucleus of the hypothalamus or ventromedial part of the ARH (Fig. 2C). As demonstrated in previous publications (Furigo et al., 2019; Teixeira et al., 2019), brain-specific GHR ablation caused a robust reduction in GH-induced pSTAT5 expression in the entire hypothalamus and brainstem (Fig. 2E,F). Additionally, BRAIN GHR KO mice exhibited a $90 \%$ reduction in the expression of $G h r$ mRNA in the whole hypothalamus, compared with control animals, as determined by qRT-PCR (Control: $1.00 \pm 0.09$; BRAIN GHR KO: $0.11 \pm 0.01 ; t_{(8)}=8.501, p<$ $0.0001)$. Together, these findings demonstrate the specificity and efficacy of our cell-specific gene deletions.
GHR ablation in TH cells or the entire brain causes increased body growth in male and female mice

To investigate the consequences of GHR ablation in different subpopulations of catecholaminergic neurons, we evaluated the body weight, body composition, naso-anal length, and the masses of different organs and tissues in DAT GHR KO, DBH GHR KO, TH GHR KO, and BRAIN GHR KO mice. Each conditional $\mathrm{KO}$ group has its own control group consisting of animals born in the same litters. In 20-week-old males, we observed that both DAT GHR KO and DBH GHR KO mice exhibited a similar body weight, lean mass, fat mass, and naso-anal length, compared with their respective control groups (Fig. 3A-H). Accordingly, the masses of the liver, spleen, heart, kidney, perigonadal adipose tissue, testicle, brain, and gastrocnemius muscle 


\section{A 8 weeks of age}

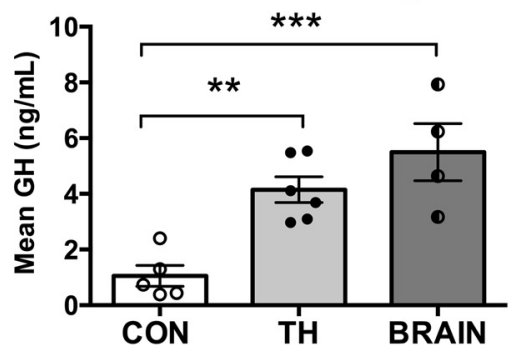

D 18 weeks of age

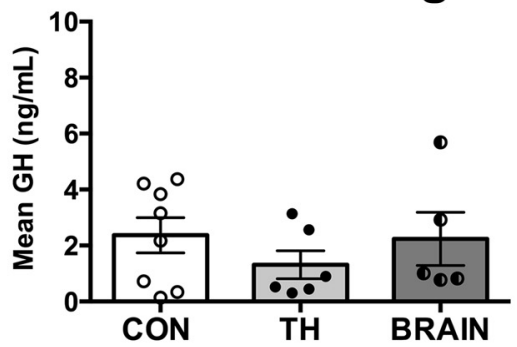

B

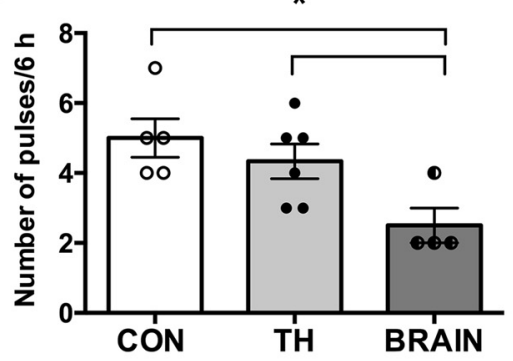

E

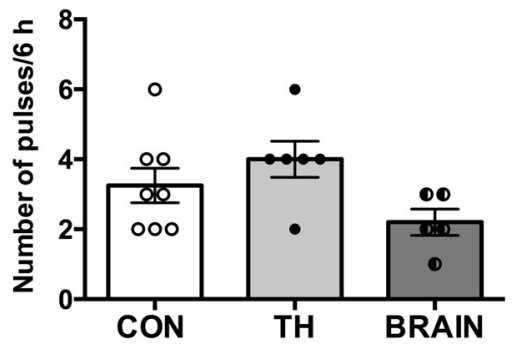

C

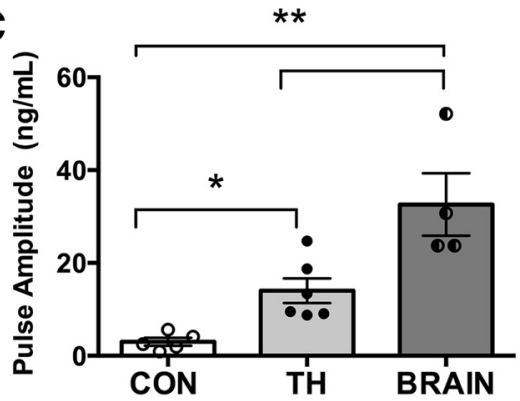

$\mathbf{F}$

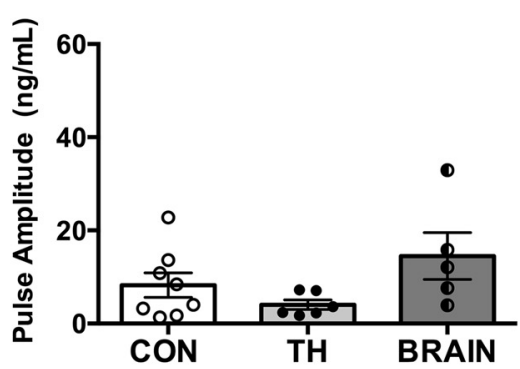

Figure 8. Loss of GH-negative feedback in TH cells or the entire brain raises GH secretion via increased pulse amplitude. $\boldsymbol{A}-\boldsymbol{C}$, Mean $\mathrm{GH}$ levels $(\boldsymbol{A})$, pulse frequency $(\boldsymbol{B})$, and pulse amplitude $(\boldsymbol{C})$ in 8-week-old control $(n=5)$, TH GHR KO $(n=6)$, and BRAIN GHR KO $(n=4)$ male mice. $\boldsymbol{D}$ - $\boldsymbol{F}$, Mean GH levels $(\boldsymbol{D})$, pulse frequency $(\boldsymbol{E})$, and pulse amplitude $(\boldsymbol{F})$ in 18 -week-old control $(n=8)$, TH GHR KO $(n=6)$, and BRAIN GHR KO $(n=5)$ male mice. The pulsatile pattern of GH secretion was determined by 36 serial blood collections in each mouse at 10 min intervals during the first $6 \mathrm{~h}$ of the light phase. ${ }^{*} p<0.05 ;{ }^{* *} p<0.01 ;{ }^{* * *} p<0.001$; one-way ANOVA and Bonferroni's multiple comparisons test. Data are mean \pm SEM.
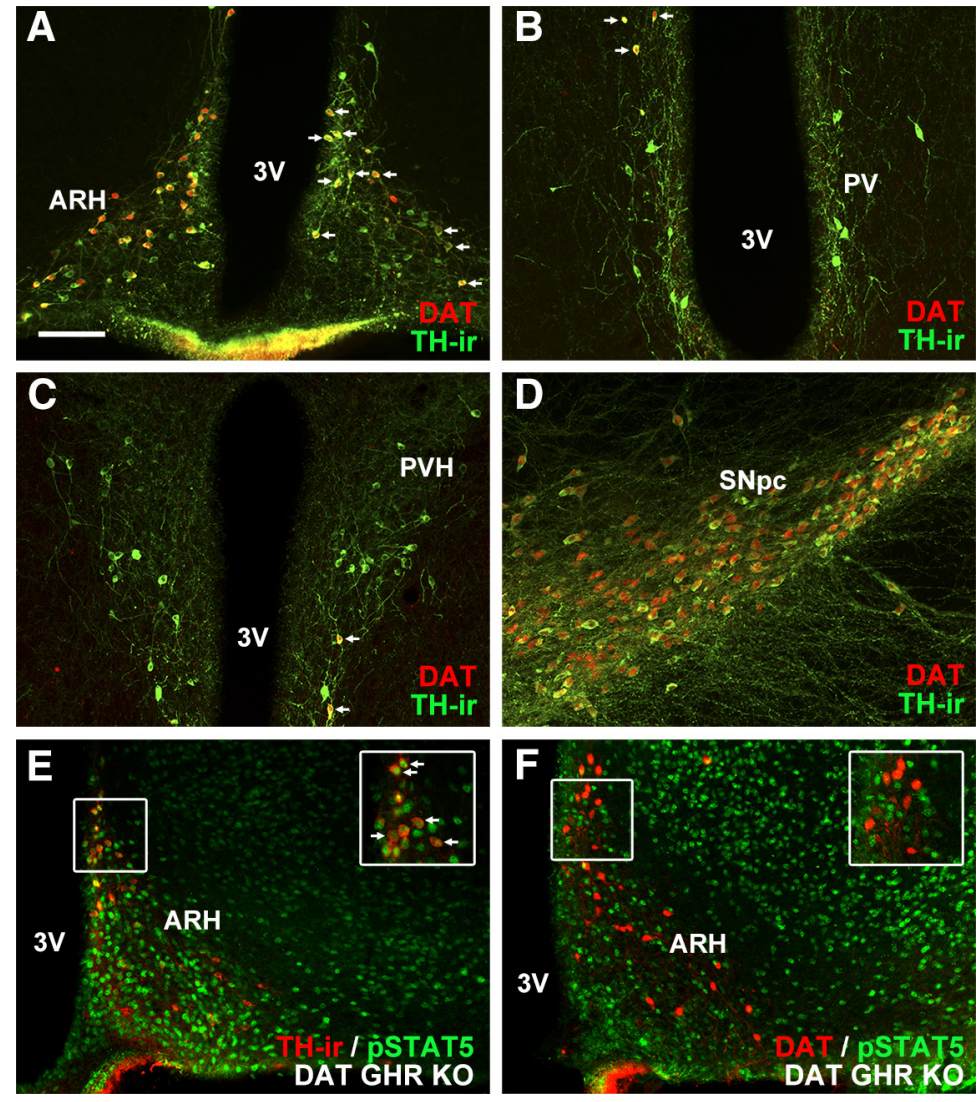

Figure 9. Partial colocalization between DAT and TH-ir in the hypothalamus. A-D, Epifluorescence photomicrographs showing DAT-expressing cells (visualized by the red tdTomato reporter protein) and TH-ir (green) in male mice. $\boldsymbol{E}$, TH-ir cells (red) are still responsive to GH (pSTAT5; green) in DAT GHR KO male mice. $\boldsymbol{F}$, Virtually no DATexpressing cells (visualized by the red tdTomato reporter protein) exhibited GH-induced PSTAT5 (green) in DAT GHR KO male mice. Insets, Higher-magnification photomicrographs of the selected area. Arrows indicate double-labeled neurons. 3V, Third ventricle. Scale bar, $100 \mu \mathrm{m}$. were similar between control groups and DAT GHR KO and DBH GHR KO mice (Figs. 4, 5). In contrast, both 10-week-old (Fig. 3I-L) and 42week-old (Fig. 3M-P) TH GHR KO mice had increased body weight, lean mass, and naso-anal length compared with the control groups. In addition, 42-week-old TH GHR KO male mice exhibited a higher liver, spleen, heart, kidney (Fig. 4), testicle, brain, and gastrocnemius masses (Fig. 5), compared with control animals. Interestingly, body fat mass (Fig. $3 K, O$ ) and perigonadal adipose tissue weight (Fig. 5I) were similar between TH GHR KO and control mice, demonstrating that the increased body weight was not caused by a higher body adiposity. Ablation of GHR in the entire brain causes loss of GH-negative feedback (Bohlen et al., 2019; Furigo et al., 2019). Thus, BRAIN GHR KO mice were studied as a reference to the effects caused by GHR ablation in catecholaminergic cells. We observed that BRAIN GHR KO male mice exhibited increased body weight, lean mass, and nasoanal length, compared with the control group (Fig. 3Q-T). BRAIN GHR KO mice also showed higher liver, spleen, heart, and kidney masses (Fig. $4 M-P$ ), whereas body fat (Fig. $3 S$ ) and perigonadal adipose tissue and testicle (Fig. $5 M, N$ ) masses had no significant differences between control and BRAIN GHR KO mice.

Possible changes in body growth were also evaluated in female mice (Fig. 6). As seen in males, 10-week-old DAT GHR KO and DBH GHR KO female mice showed similar body weight, lean mass, and body fat mass, compared with their respective control groups (Fig. 6A-F). 
A

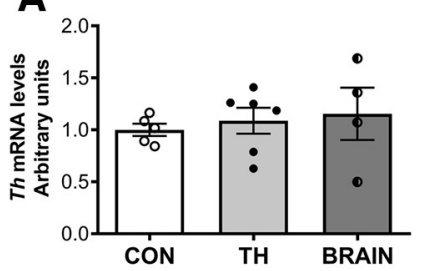

B

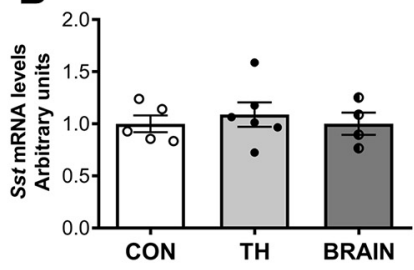

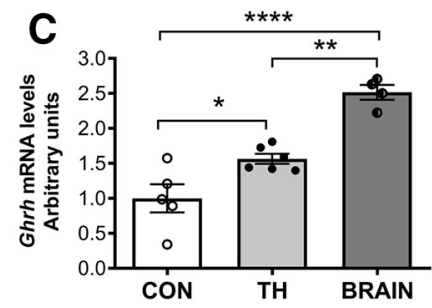
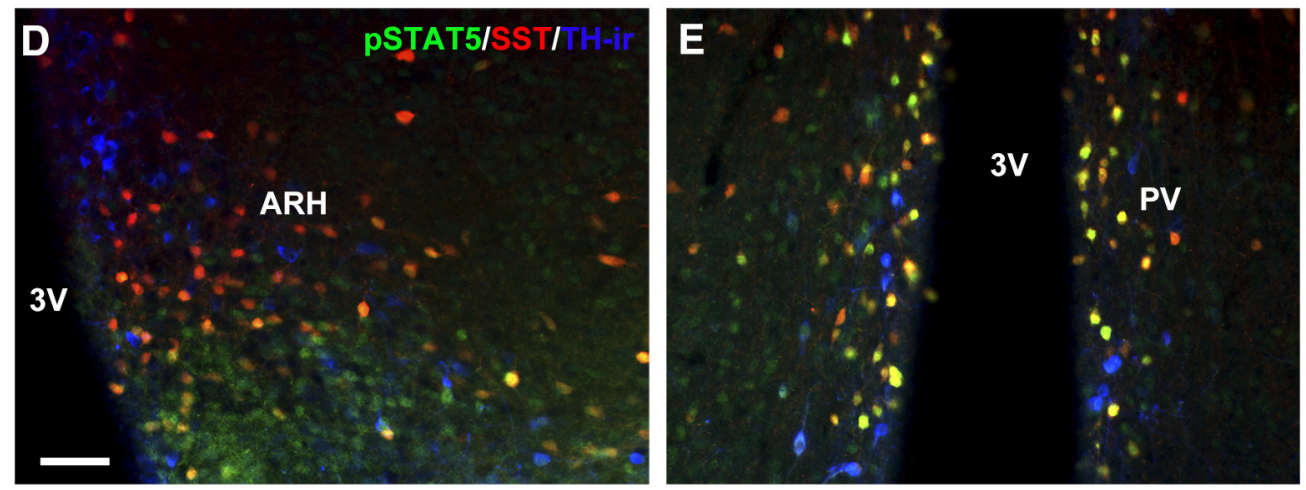

Figure 10. GHR ablation in TH cells leads to increased hypothalamic expression of Ghrh mRNA. $\boldsymbol{A}-\boldsymbol{C}$, Gene expression analysis in the whole hypothalamus of 8-week-old control ( $n=5$ ), TH GHR KO $(n=6)$, or BRAIN GHR KO $(n=4)$ male mice. ${ }^{*} p<0.05$; ${ }^{* *} p<0.01$; ${ }^{* * *} p<0.0001$; one-way ANOVA and Bonferroni's multiple comparisons test. Data are mean \pm SEM. $\boldsymbol{D}, \boldsymbol{E}$, Triple immunofluorescence staining to identify whether SST neurons (visualized by the red tdTomato reporter protein) express TH-ir (blue) and are responsive to GH (pSTAT5; green) in male mice. 3V, Third ventricle. Scale bar, $50 \mu \mathrm{m}$.

In contrast, both TH GHR KO and BRAIN GHR KO female mice exhibited increased body weight and lean mass in comparison with control females (Fig. 6G,H and Fig. 6J,K). No differences were observed in body fat mass between TH GHR KO and BRAIN GHR KO females and control mice (Fig. $6 I$ and Fig. $6 L$ ).

Loss of GH-negative feedback in TH cells or the entire brain raises $\mathrm{GH}$ secretion via increased pulse amplitude

To test whether the absence of $\mathrm{GH}$ action in $\mathrm{TH}$ cells leads to increases in GH secretion, we initially measured serum IGF-1 levels in 10-week-old TH GHR KO and control male mice. We observed increased serum IGF-1 levels in TH GHR KO mice $(861 \pm 43 \mathrm{ng} / \mathrm{ml}$ ) compared with control animals (635 $\pm 47 \mathrm{ng} /$ $\left.\mathrm{ml} ; t_{(17)}=3.532, p=0.0026\right)$. Then, we analyzed the pulsatile secretion of GH in 8- or 18-week-old male mice (Figs. 7, 8). Both 8-week-old TH GHR KO and BRAIN GHR KO mice exhibited higher mean $\mathrm{GH}$ levels during the period analyzed, compared with control group (Figs. $7 A-C, 8 A$ ). Therefore, the increased body growth of TH GHR KO and BRAIN GHR KO mice was probably caused by the greatly increased GH secretion. To determine which parameters of pulsatile GH secretion were affected by the loss of GH-negative feedback, the frequency and the amplitude of pulses were determined. Eight-week old BRAIN GHR $\mathrm{KO}$ mice displayed a reduced number of pulses during the $6 \mathrm{~h}$ blood collection period, compared with control animals (Fig. $8 B$ ). On the other hand, a marked increase in pulse amplitude was observed in both 8-week-old TH GHR KO mice, compared with control animals, and BRAIN GHR KO mice, compared with all groups (Figs. $7 A-C, 8 C$ ). To investigate whether the changes in $\mathrm{GH}$ secretion continue in older animals, the pulsatile secretion of GH was also evaluated in 18-week-old male mice. In this case, TH GHR KO and BRAIN GHR KO mice showed similar mean GH levels, pulse frequency, and pulse amplitude, compared with control animals (Figs. $7 D-F, 8 D-F$ ). These findings indicate that the loss of GH-negative feedback in $\mathrm{TH}$ cells increases $\mathrm{GH}$ secretion via higher pulse amplitude, without altering pulse frequency. Furthermore, these neuroendocrine defects decrease with aging.

\section{Partial colocalization between DAT and TH in the hypothalamus}

Our findings so far indicate that $\mathrm{GH}$ action on $\mathrm{TH}$-positive neurons, but not on DAT- or DBH-expressing cells, is required for typical GH secretion and consequently normal somatic growth. Whereas $\mathrm{DBH}$ expression reliably represents the distribution of noradrenergic/adrenergic cells (Parlato et al., 2007), there is evidence that only part of TH cells in the forebrain expresses DAT (Turiault et al., 2007; Yip et al., 2018). In this regard, we performed a colocalization in male mice between DAT-expressing cells (using the tdTomato reporter protein) and $\mathrm{TH}$-ir in several hypothalamic areas and in the $\mathrm{SNpc}$, as a positive reference (Fig. 9). We observed that $56 \pm 3 \%$ of $\mathrm{TH}$-ir neurons in the $\mathrm{ARH}$ (Fig. 9A), $28 \pm 2 \%$ in the PV (Fig. $9 B$ ), and $9 \pm 8 \%$ in the PVH (Fig. 9C) expressed tdTomato. In contrast, $95 \pm 1 \%$ of $\mathrm{TH}$-ir neurons in the SNpc expressed tdTomato (Fig. 9D). Thus, it is likely that only a subpopulation of TH-positive cells in the hypothalamus was actually affected by the GHR ablation using the DAT-IRES-Cre mice. To confirm that the GHR deletion only affected the subpopulation of DAT-expressing neurons in the hypothalamus of DAT GHR KO mice, GH-induced pSTAT5 was colocalized with either TH-ir (Fig. 9E), or tdTomato, as marker of DAT-expressing neurons only (Fig. 9F). Interestingly, while GH-induced pSTAT5 was clearly observed in hypothalamic TH-ir cells (Fig. 9E), DAT-expressing cells did not contain pSTAT5 (Fig. 9F). Together, these results demonstrate that $\mathrm{TH}$ neurons that do not express DAT are required for the auto-regulation of $\mathrm{GH}$ secretion via a negative-feedback mechanism.

GHR ablation in TH cells increases hypothalamic expression of GHRH, although a very small percentage of GHRH cells are responsive to $\mathrm{GH}$ and express $\mathrm{TH}$

To determine how GHR ablation in TH cells or the entire brain affects the hypothalamic expression of classical neuropeptides 

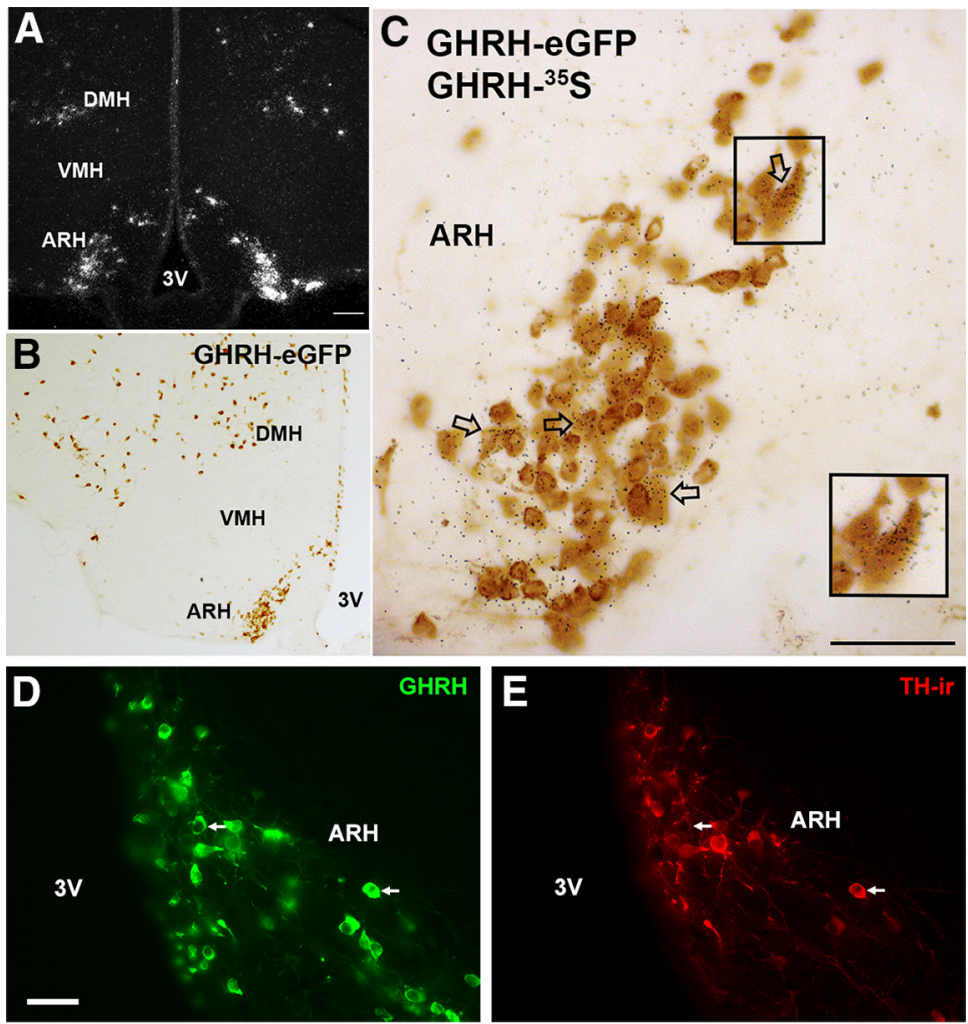

$\mathbf{F}$

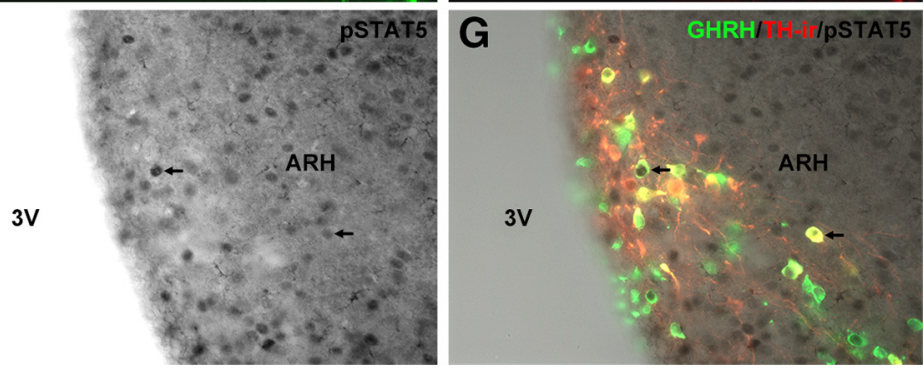

Figure 11. A very small percentage of GHRH cells are responsive to GH and express TH. $\boldsymbol{A}$, Representative darkfield digital image showing the distribution of Ghrh mRNA in the ARH by ISH. $\boldsymbol{B}$, Brightfield digital image showing the distribution of GHRH-eGFP-positive cells in the ARH. $\boldsymbol{C}$, Higher magnification of $\boldsymbol{B}$ showing colocalization (arrows) of Ghrh mRNA (silver grains) and GHRH reporter gene (GFP-immunoreactive neurons in brown). $\mathbf{D}-\mathbf{G}$, Triple-immunofluorescence staining to identify whether GHRH neurons (visualized by the GFP) express TH-ir (red) and are responsive to GH (pSTAT5; black nuclear staining). Arrows indicate triple-labeled neurons. $3 \mathrm{~V}$, Third ventricle; $\mathrm{DMH}$, dorsomedial nucleus of the hypothalamus; VMH, ventromedial nucleus of the hypothalamus. Scale bars: $A, B, 100 \mu \mathrm{m} ; C, 50 \mu \mathrm{m} ; \mathbf{D}-\mathbf{G}, 30 \mu \mathrm{m}$.

that regulate $\mathrm{GH}$ secretion, we collected the hypothalamus of 8week-old control, TH GHR KO, and BRAIN GHR KO male mice. We initially determined the mRNA levels of $T h$, but no significant differences between the groups were observed (Fig. $10 A)$. Then, Sst and Ghrh mRNA levels were assessed in the whole hypothalamus. Sst mRNA levels were also similar between the groups (Fig. 10B). In contrast, TH GHR KO mice showed increased Ghrh mRNA expression compared with control animals, and BRAIN GHR KO mice exhibited higher Ghrh mRNA levels compared with both control and TH GHR KO mice (Fig. 10C).

Using reporter mice that allow the visualization of SST or GHRH cells, we performed a triple immunofluorescence labeling to identify whether these neurons coexpress $\mathrm{TH}$ and are responsive to GH. Although a large percentage of SST neurons, especially in the periventricular zone of the hypothalamus, expressed pSTAT5 in response to GH, as expected (Burton et al., 1992), no triple-labeled neurons were observed (Fig. 10D,E). GHRH-Cre mouse was used in a previous publication (Rupp et al., 2018), but details about the percentage of GHRH neurons that show Cre recombinase activity in the ARH were not provided. Thus, using brain sections of Ghrh ${ }^{\text {Cre/- } / e G F P-L 10 a ~ m i c e, ~ d u a l-l a b e l e d ~}$ neurons coexpressing eGFP immunoreactivity and GHRH ${ }^{35} \mathrm{~S}$ (silver grains) were quantified in the ARH (Fig. $11 A-C$ ). One section and one side of 2 adult female mice were quantified. Only cells containing silver grains (Ghrh mRNA) $3 \times$ above background levels overlaying a brown (DAB-stained) cytoplasm were considered positive. We found that $52.5 \pm 7.5 \%$ of GHRH-Cre eGFP neurons coexpress Ghrh mRNA in adult mice (Fig. $11 A-C$ ). Of note, very few GHRH hybridization signal was observed outside GFP-immunoreactive neurons. Next, we determined whether GHRH-Cre eGFP neurons in the ARH coexpress $\mathrm{TH}$ and are responsive to $\mathrm{GH}$. GH-induced pSTAT5 was observed in $8.7 \pm 1.9 \%$ of GHRH cells (data from 2 females and 1 male), compared with $1.3 \pm 0.7 \%$ in PBS-injected mice $\left(t_{(5)}=4.053\right.$, $p=0.0098$; data from 2 females and 2 males; Fig. 11D-G). As shown in previous studies (Phelps et al., 2003; Bouyer et al., 2007), $13 \pm 1 \%$ of $\mathrm{GHRH}$ neurons in the $\mathrm{ARH}$ coexpressed $\mathrm{TH}$ (Fig. 11D-G). However, only $2.5 \pm 1.6 \%$ of GHRH neurons coexpressed TH and pSTAT5 after an acute GH injection, compared with $0.9 \pm 0.7 \%$ in PBSinjected mice $\left(t_{(5)}=0.9904, p=0.3675\right.$; Fig. $11 D-G)$. Therefore, although the absence of GHR in TH cells leads to increased Ghrh mRNA expression, only a very small percentage of GHRH cells are responsive to $\mathrm{GH}$ and express TH.

\section{Discussion}

The secretion of pituitary hormones is primarily regulated by negative-feedback systems. In most of these feedback loops, specific hypothalamic neurons detect changes in hormone levels and modulate pituitary function to maintain hormone concentrations within a narrow range (Steyn et al., 2016). Regarding the somatotropic axis, the common knowledge indicates that $\mathrm{GH}$ feeds back mostly to SST and GHRH neurons (Steyn et al., 2016). Although SST and GHRH neurons are indispensable for the regulation of the somatotropic axis (Donahue and Beamer, 1993; Zeyda et al., 2001), interneurons that express GHR may also play a role regulating GH secretion. Both noradrenergic (Lal et al., 1975; Bluet-Pajot et al., 1992; Iqbal et al., 2005) and dopaminergic (Díaz-Torga et al., 2002; Noaín et al., 2013) neurotransmission have also been associated with the regulation of GH secretion. However, our study revealed that not only a high percentage of catecholaminergic neurons are directly responsive to $\mathrm{GH}$, but the absence of GHR from $\mathrm{TH}$ cells disturbs the hypothalamic control of $\mathrm{GH}$ secretion, leading to increases in GH pulse amplitude and body growth. Remarkably, the increased mean GH levels between 
TH GHR KO mice and BRAIN GHR $\mathrm{KO}$ mice was similar, highlighting that the lack of GH action on TH neurons produces defects equivalent to the absence of GHR in the entire brain. Since GHR deletion in TH- and Nestinexpressing cells caused identical alterations in the body growth of males and females, we believe that the increased $\mathrm{GH}$ secretion observed in experiments performed only in males occurs in females as well. However, GH secretion presents significant sex differences (van den Berg et al., 1996; Jaffe et al., 1998). Thus, future studies are still necessary to confirm that the higher body growth observed in TH GHR KO and BRAIN GHR KO female mice is also caused by increased GH secretion.

The infusion of $\alpha 2$-adrenergic agonists has been widely used as a clinical test to evaluate possible defects in GH production in children and adolescents (Gil-Ad et al., 1979; Steyn et al., 2016). The discovery that $\sim 90 \%$ of noradrenergic cells of the LC are directly responsive to $\mathrm{GH}$ indicates that the noradrenergic control of GH secretion might integrate a feedback control loop. However, ablation of GHR in DBH-positive cells caused no changes in body growth. Thus, the role of GH action on the LC remains unknown and deserves further investigation. DAT GHR KO mice also exhibited similar body growth compared with control littermates, suggesting that GH signaling in DAT-expressing cells is not required for the regulation of GH secretion. DAT is responsible for the reuptake of dopamine in the synaptic cleft. Although DAT expression has been used as a marker of dopamine neurons, our findings and previous studies (Turiault et al., 2007; Yip et al., 2018) indicate that the majority of TH-positive neurons in the hypothalamus does not express DAT. Hypothalamic dopaminergic neurons are frequently associated with the regulation of anterior pituitary hormone secretion, releasing neuromodulators into the hypophyseal portal system without requiring DAT for the reuptake of dopamine (Brown et al., 2016). Since TH GHR KO mice exhibited increased body growth, whereas both DAT GHR KO and DBH GHR KO mice showed a normal phenotype, our findings indicate that a group of non-DAT dopaminergic neurons (TH-positive, but DBH-negative) is critical to the auto-regulation of GH secretion via a negative-feedback loop. Prolactin release is mainly controlled by tuberoinfundibular dopaminergic neurons (Brown et al., 2016). Thus, the regulation of prolactin and GH secretion seems to be somehow coordinated by these hypothalamic dopaminergic neurons. Accordingly, dopamine agonists are clinically used to treat hyperprolactinemia and acromegaly (Jaffe and Barkan, 1994; Diez and Iglesias, 2000). These drugs inhibit GH secretion by acting in pituitary somatotropic cells (Spada et al., 1994; BenShlomo et al., 2017) or via hypothalamic mechanisms (Vance et al., 1987; West et al., 1997). However, some TH neurons in the hypothalamus possibly produce L-DOPA as an end-product rather than dopamine (Meister et al., 1988; Komori et al., 1991). Although their function is not well understood, there is evidence of cooperative synthesis of dopamine by different neurons that express complementary enzymes of the pathway for dopamine biosynthesis (Ugrumov et al., 2002; Kurina et al., 2017). Thus, the exact neurotransmitters used by these $\mathrm{TH}^{+} /$ $\mathrm{DAT}^{-} / \mathrm{DBH}^{-}$neurons to regulate $\mathrm{GH}$ secretion still need to be identified.

Another question investigated was whether these catecholaminergic neurons that regulate the somatotropic axis would be the same cells that produce SST or GHRH. SST neurons are distributed in hypothalamic nuclei that contain $\mathrm{GH}$-responsive $\mathrm{TH}$ cells (Fodor et al., 2006). In agreement with previous studies that identified a large percentage of SST neurons expressing GHR in the PV/PVH (Burton et al., 1992), we also observed a large amount of SST neurons in these areas expressing GH-induced pSTAT5. Some colocalizations between SST and pSTAT5 were also observed in the ARH. However, virtually no triple-labeled pSTAT5/SST/TH cells were found in these brain areas. Histologic and molecular data indicate that part of GHRH neurons express TH (Bouyer et al., 2007; Campbell et al., 2017). Surprisingly, scarce information exists regarding the expression of GHR in GHRH neurons. As far as we know, one study reported that $<10 \%$ of ARH GHRH neurons express Ghr mRNA (Burton et al., 1995). Using pSTAT5 as a marker of GH-responsive cells, we confirmed the small number of GHRHresponsive neurons and $<3 \%$ of them express both $\mathrm{TH}$ - and GH-induced pSTAT5. Therefore, TH cells that regulate GH secretion via negative feedback are basically DAT-, DBH-, SST-, and GHRH-negative, representing a yet unidentified group of neurons critical to the auto-regulation of the somatotropic axis.

Hypothalamic Ghrh mRNA expression was disturbed by GHR deletion in TH cells or the entire brain. Rather than a downregulation of Ghrh expression, which would indicate an attempt to correct high circulating GH levels via negative feedback, we observed increased Ghrh expression in the hypothalamus of TH GHR KO and BRAIN GHR KO mice. Thus, our findings confirm the results of previous studies indicating that GHRH neurons are influenced by variations in GH levels (Chomczynski et al., 1988; Bertherat et al., 1993; de Gennaro Colonna et al., 1993), and further demonstrate that this auto-regulation involves interneurons that first detect changes in GH levels and, in response, regulate GHRH expression. Thus, we hypothesize that the absence of GH action on these $\mathrm{TH}^{+} / \mathrm{DAT}^{-} /$ 
$\mathrm{DBH}^{-}$neurons led to either increased excitatory signal or decreased inhibitory tone on GHRH neurons. In both cases, GHRH neurons represent the final path for the stimulation of $\mathrm{GH}$ secretion caused by the lack of GH-negative-feedback effect on these neurons. Notably, Ghrh expression was higher in BRAIN GHR KO mice compared with TH GHR KO mice. Thus, Ghrh expression is not only regulated by $\mathrm{GH}$ action on $\mathrm{TH}$ cells, but also by another neuronal population that causes an additive effect. Although $<10 \%$ of GHRH neurons are directly responsive to $\mathrm{GH}$, ablation of GHR in this subgroup of GHRH neurons may account for the upregulation in hypothalamic Ghrh expression. Alternatively, another population of $\mathrm{GH}$-responsive interneurons may also affect Ghrh expression. However, we cannot rule out the possibility that these $\mathrm{TH}^{+} / \mathrm{DAT}^{-} / \mathrm{DBH}^{-}$neurons might regulate $\mathrm{GH}$ secretion through the hypophyseal portal system.

Although both TH GHR KO and BRAIN GHR KO mice exhibited equivalent increases in mean GH levels, the pulsatile pattern of GH secretion was differently affected in these mouse models. BRAIN GHR KO mice showed reduced GH pulse frequency that was compensated by a robust increase in $\mathrm{GH}$ pulse amplitude. The absence of GH-negative feedback in TH cells also led to increased pulse amplitude. Intracerebroventricular administration of GHR antagonist increases GH pulse amplitude without affecting the number of GH pulses (Nass et al., 2000a). Despite the fact that the differences in body growth persists in older TH GHR KO and BRAIN GHR KO mice, the pulsatile pattern of GH secretion was normalized in 18-week-old $\mathrm{KO}$ mice. Previous studies have already shown a significant decline in $\mathrm{GH}$ secretion throughout adulthood in mice (Huang et al., 2012; Xie et al., 2015). Interestingly, aging-related decline in GH secretion is caused by a decrease in GH pulse amplitude, whereas pulse frequency remains unchanged (Russell-Aulet et al., 2001). Therefore, negative-feedback mechanisms on $\mathrm{TH}$ cells may play a role controlling $\mathrm{GH}$ secretion until early adulthood; and once $\mathrm{GH}$ secretion decreases after this period, the importance of this TH/GHRH/pituitary system declines with aging or can be compensated by multiple redundant mechanisms that exist to control GH secretion (Steyn et al., 2016).

In conclusion, we unraveled a critical and previously unidentified group of catecholaminergic interneurons that are apt to sense changes in circulating GH levels and consequently regulate Ghrh expression to auto-control the somatotropic axis. Based on these findings, we propose a reevaluation of the short-loop feedbacks that regulate $\mathrm{GH}$ secretion to include these $\mathrm{TH}^{+} / \mathrm{DAT}^{-}$/ $\mathrm{DBH}^{-}$cells as key interneurons that sense circulating $\mathrm{GH}$ levels and use GHRH neurons as downstream effectors to regulate the somatotropic axis (Fig. 12).

\section{References}

Ben-Shlomo A, Liu NA, Melmed S (2017) Somatostatin and dopamine receptor regulation of pituitary somatotroph adenomas. Pituitary 20:9399.

Bertherat J, Timsit J, Bluet-Pajot MT, Mercadier JJ, Gourdji D, Kordon C, Epelbaum J (1993) Chronic growth hormone (GH) hypersecretion induces reciprocal and reversible changes in mRNA levels from hypothalamic GH-releasing hormone and somatostatin neurons in the rat. J Clin Invest 91:1783-1791.

Bluet-Pajot MT, Mounier F, Durand D, Kordon C, Llorens-Cortes C, Videau C, Epelbaum J (1992) 6-Hydroxydopamine lesions of the locus coeruleus induce a paradoxical increase in growth hormone secretion in male rats. J Neuroendocrinol 4:9-14.

Bohlen TM, Zampieri TT, Furigo IC, Teixeira PD, List EO, Kopchick J, Donato J Jr, Frazao R (2019) Central growth hormone signaling is not required for the timing of puberty. J Endocrinol 243:161-173.
Bouyer K, Loudes C, Robinson IC, Epelbaum J, Faivre-Bauman A (2007) Multiple colocalizations in arcuate GHRH-eGFP neurons in the mouse hypothalamus. J Chem Neuroanat 33:1-8.

Brown RS, Kokay IC, Phillipps HR, Yip SH, Gustafson P, Wyatt A, Larsen CM, Knowles P, Ladyman SR, LeTissier P, Grattan DR (2016) Conditional deletion of the prolactin receptor reveals functional subpopulations of dopamine neurons in the arcuate nucleus of the hypothalamus. J Neurosci 36:9173-9185.

Burton KA, Kabigting EB, Clifton DK, Steiner RA (1992) Growth hormone receptor messenger ribonucleic acid distribution in the adult male rat brain and its colocalization in hypothalamic somatostatin neurons. Endocrinology 131:958-963.

Burton KA, Kabigting EB, Steiner RA, Clifton DK (1995) Identification of target cells for growth hormone's action in the arcuate nucleus. Am J Physiol 269:E716-E722.

Campbell JN, Macosko EZ, Fenselau H, Pers TH, Lyubetskaya A, Tenen D, Goldman M, Verstegen AM, Resch JM, McCarroll SA, Rosen ED, Lowell BB, Tsai LT (2017) A molecular census of arcuate hypothalamus and median eminence cell types. Nat Neurosci 20:484-496.

Catzeflis C, Pierroz DD, Rohner-Jeanrenaud F, Rivier JE, Sizonenko PC, Aubert ML (1993) Neuropeptide Y administered chronically into the lateral ventricle profoundly inhibits both the gonadotropic and the somatotropic axis in intact adult female rats. Endocrinology 132:224-234.

Chan Y, Steiner R, Clifton D (1996) Regulation of hypothalamic neuropeptide-Y neurons by growth hormone in the rat. Endocrinology 137:13191325.

Chomczynski P, Downs TR, Frohman LA (1988) Feedback regulation of growth hormone $(\mathrm{GH})$-releasing hormone gene expression by $\mathrm{GH}$ in rat hypothalamus. Mol Endocrinol 2:236-241.

de Gennaro Colonna V, Fidone F, Cocchi D, Müller EE (1993) Feedback effects of growth hormone on growth hormone-releasing hormone and somatostatin are not evident in aged rats. Neurobiol Aging 14:503-507.

Díaz-Torga G, Feierstein C, Libertun C, Gelman D, Kelly MA, Low MJ, Rubinstein M, Becú-Villalobos D (2002) Disruption of the D2 dopamine receptor alters GH and IGF-I secretion and causes dwarfism in male mice. Endocrinology 143:1270-1279.

Diez JJ, Iglesias P (2000) Current management of acromegaly. Expert Opin Pharmacother 1:991-1006.

Donahue LR, Beamer WG (1993) Growth hormone deficiency in 'little' mice results in aberrant body composition, reduced insulin-like growth factorI and insulin-like growth factor-binding protein-3 (IGFBP-3), but does not affect IGFBP-2, -1 or -4. J Endocrinol 136:91-104.

Fodor M, Kordon C, Epelbaum J (2006) Anatomy of the hypophysiotropic somatostatinergic and growth hormone-releasing hormone system minireview. Neurochem Res 31:137-143.

Furigo IC, Metzger M, Teixeira PD, Soares CR, Donato J Jr (2017) Distribution of growth hormone-responsive cells in the mouse brain. Brain Struct Funct 222:341-363.

Furigo IC, Teixeira PD, de Souza GO, Couto GC, Romero GG, Perello M, Frazao R, Elias LL, Metzger M, List EO, Kopchick JJ, Donato J Jr (2019) Growth hormone regulates neuroendocrine responses to weight loss via AgRP neurons. Nat Commun 10:662.

Gahete MD, Cordoba-Chacon J, Anadumaka CV, Lin Q, Bruning JC, Kahn CR, Luque RM, Kineman RD (2011) Elevated GH/IGF-I, due to somatotrope-specific loss of both IGF-I and insulin receptors, alters glucose homeostasis and insulin sensitivity in a diet-dependent manner. Endocrinology 152:4825-4837.

Gil-Ad I, Topper E, Laron Z (1979) Oral clonidine as a growth hormone stimulation test. Lancet 2:278-279.

Huang L, Steyn FJ, Tan HY, Xie TY, Veldhuis JD, Ngo ST, Chen C (2012) The decline in pulsatile GH secretion throughout early adulthood in mice is exacerbated by dietary-induced weight gain. Endocrinology 153:43804388.

Iqbal J, Manley TR, Yue Q, Namavar MR, Clarke IJ (2005) Noradrenergic regulation of hypothalamic cells that produce growth hormone-releasing hormone and somatostatin and the effect of altered adiposity in sheep. J Neuroendocrinol 17:341-352.

Jaffe CA, Barkan AL (1994) Acromegaly: recognition and treatment. Drugs 47:425-445.

Jaffe CA, Ocampo-Lim B, Guo W, Krueger K, Sugahara I, DeMott-Friberg R, Bermann M, Barkan AL (1998) Regulatory mechanisms of growth hormone secretion are sexually dimorphic. J Clin Invest 102:153-164. 
Kamegai J, Minami S, Sugihara H, Hasegawa O, Higuchi H, Wakabayashi I (1996) Growth hormone receptor gene is expressed in neuropeptide Y neurons in hypothalamic arcuate nucleus of rats. Endocrinology 137:2109-2112.

Komori K, Fujii T, Nagatsu I (1991) Do some tyrosine hydroxylase-immunoreactive neurons in the human ventrolateral arcuate nucleus and globus pallidus produce only L-dopa? Neurosci Lett 133:203-206.

Kurina AU, Pronina TS, Dilmukhametova LK, Maleev GV, Ugrumov MV (2017) Cooperative synthesis of dopamine in rat mediobasal hypothalamus as a compensatory mechanism in hyperprolactinemia. Biochem Mosc 82:366-372.

Lal S, Tolis G, Martin SB, Brown GM, Guyda H (1975) Effect of clonidine on growth hormone, prolactin, luteinizing hormone, follicle-stimulating hormone, and thyroid-stimulating hormone in the serum of normal men. J Clin Endocrinol Metab 41:827-832.

List EO, Berryman DE, Funk K, Gosney ES, Jara A, Kelder B, Wang X, Kutz L, Troike K, Lozier N, Mikula V, Lubbers ER, Zhang H, Vesel C, Junnila RK, Frank SJ, Masternak MM, Bartke A, Kopchick JJ (2013) The role of $\mathrm{GH}$ in adipose tissue: lessons from adipose-specific $\mathrm{GH}$ receptor genedisrupted mice. Mol Endocrinol 27:524-535.

Meister B, Hokfelt T, Steinbusch HW, Skagerberg G, Lindvall O, Geffard M, Joh TH, Cuello AC, Goldstein M (1988) Do tyrosine hydroxylase-immunoreactive neurons in the ventrolateral arcuate nucleus produce dopamine or only L-dopa? J Chem Neuroanat 1:59-64.

Minami S, Kamegai J, Sugihara H, Suzuki N, Wakabayashi I (1998) Growth hormone inhibits its own secretion by acting on the hypothalamus through its receptors on neuropeptide $\mathrm{Y}$ neurons in the arcuate nucleus and somatostatin neurons in the periventricular nucleus. Endocr J 45 Suppl:S19-S26.

Morita S, Yamashita S, Melmed S (1987) Insulin-like growth factor I action on rat anterior pituitary cells: effects of intracellular messengers on growth hormone secretion and messenger ribonucleic acid levels. Endocrinology 121:2000-2006.

Nass R, Toogood AA, Hellmann P, Bissonette E, Gaylinn B, Clark R, Thorner MO (2000a) Intracerebroventricular administration of the rat growth hormone $(\mathrm{GH})$ receptor antagonist $\mathrm{G} 118 \mathrm{R}$ stimulates $\mathrm{GH}$ secretion: evidence for the existence of short loop negative feedback of GH. J Neuroendocrinol 12:1194-1199.

Nass R, Gilrain J, Anderson S, Gaylinn B, Dalkin A, Day R, Peruggia M, Thorner MO (2000b) High plasma growth hormone (GH) levels inhibit expression of $\mathrm{GH}$ secretagogue receptor messenger ribonucleic acid levels in the rat pituitary. Endocrinology 141:2084-2089.

Nass R, Farhy LS, Liu J, Prudom CE, Johnson ML, Veldhuis P, Pezzoli SS, Oliveri MC, Gaylinn BD, Geysen HM, Thorner MO (2008) Evidence for acyl-ghrelin modulation of growth hormone release in the fed state. J Clin Endocrinol Metab 93:1988-1994.

Noaín D, Pérez-Millán MI, Bello EP, Luque GM, Casas Cordero R, Gelman DM, Peper M, Tornadu IG, Low MJ, Becú-Villalobos D, Rubinstein M (2013) Central dopamine D2 receptors regulate growth-hormone-dependent body growth and pheromone signaling to conspecific males. J Neurosci 33:5834-5842.

Parlato R, Otto C, Begus Y, Stotz S, Schutz G (2007) Specific ablation of the transcription factor CREB in sympathetic neurons surprisingly protects against developmentally regulated apoptosis. Development 134:16631670.

Pellegrini E, Bluet-Pajot MT, Mounier F, Bennett P, Kordon C, Epelbaum J (1996) Central administration of a growth hormone $(\mathrm{GH})$ receptor mRNA antisense increases GH pulsatility and decreases hypothalamic somatostatin expression in rats. J Neurosci 16:8140-8148.

Phelps CJ, Romero MI, Hurley DL (2003) Growth hormone-releasing hormone-producing and dopaminergic neurones in the mouse arcuate nucleus are independently regulated populations. J Neuroendocrinol $15: 280-288$

Rupp AC, Allison MB, Jones JC, Patterson CM, Faber CL, Bozadjieva N, Heisler LK, Seeley RJ, Olson DP, Myers MG Jr (2018) Specific subpopulations of hypothalamic leptin receptor-expressing neurons mediate the effects of early developmental leptin receptor deletion on energy balance. Mol Metab 14:130-138.

Russell-Aulet M, Dimaraki EV, Jaffe CA, DeMott-Friberg R, Barkan AL (2001) Aging-related growth hormone (GH) decrease is a selective hypothalamic GH-releasing hormone pulse amplitude mediated phenomenon. J Gerontol A Biol Sci Med Sci 56:M124-M129.

Spada A, Bassetti M, Reza-Elahi F, Arosio M, Gil-Del-Alamo P, Vallar L (1994) Differential transduction of dopamine signal in different subtypes of human growth hormone-secreting adenomas. J Clin Endocrinol Metab 78:411-417.

Steyn FJ, Tolle V, Chen C, Epelbaum J (2016) Neuroendocrine regulation of growth hormone secretion. Compr Physiol 6:687-735.

Steyn FJ, Huang L, Ngo ST, Leong JW, Tan HY, Xie TY, Parlow AF, Veldhuis JD, Waters MJ, Chen C (2011) Development of a method for the determination of pulsatile growth hormone secretion in mice. Endocrinology 152:3165-3171

Teixeira PD, Couto GC, Furigo IC, List EO, Kopchick JJ, Donato J Jr (2019) Central growth hormone action regulates metabolism during pregnancy. Am J Physiol Endocrinol Metab 317:E925-E940.

Turiault M, Parnaudeau S, Milet A, Parlato R, Rouzeau JD, Lazar M, Tronche F (2007) Analysis of dopamine transporter gene expression pattern: generation of DAT-iCre transgenic mice. FEBS J 274:3568-3577.

Ugrumov M, Melnikova V, Ershov P, Balan I, Calas A (2002) Tyrosine hydroxylase- and/or aromatic L-amino acid decarboxylase-expressing neurons in the rat arcuate nucleus: ontogenesis and functional significance. Psychoneuroendocrinology 27:533-548.

van den Berg G, Veldhuis JD, Frölich M, Roelfsema F (1996) An amplitudespecific divergence in the pulsatile mode of growth hormone $(\mathrm{GH})$ secretion underlies the gender difference in mean GH concentrations in men and premenopausal women. J Clin Endocrinol Metab 81:2460-2467.

Vance ML, Kaiser DL, Frohman LA, Rivier J, Vale WW, Thorner MO (1987) Role of dopamine in the regulation of growth hormone secretion: dopamine and bromocriptine augment growth hormone (GH)-releasing hormone-stimulated GH secretion in normal man. J Clin Endocrinol Metab 64:1136-1141.

Vidal A, Zhang Q, Medigue C, Fabre S, Clement F (2012) DynPeak: an algorithm for pulse detection and frequency analysis in hormonal time series. PLoS One 7:e39001.

Wagner C, Caplan SR, Tannenbaum GS (1998) Genesis of the ultradian rhythm of GH secretion: a new model unifying experimental observations in rats. Am J Physiol 275:E1046-1054

West CR, Lookingland KJ, Tucker HA (1997) Regulation of growth hormone-releasing hormone and somatostatin from perifused, bovine hypothalamic slices: II. Dopamine receptor regulation. Domest Anim Endocrinol 14:349-357.

Xie TY, Ngo ST, Veldhuis JD, Jeffery PL, Chopin LK, Tschop M, Waters MJ, Tolle V, Epelbaum J, Chen C, Steyn FJ (2015) Effect of deletion of ghrelin-O-acyltransferase on the pulsatile release of growth hormone in mice. J Neuroendocrinol 27:872-886.

Yip SH, York J, Hyland B, Bunn SJ, Grattan DR (2018) Incomplete concordance of dopamine transporter Cre (DAT(IREScre))-mediated recombination and tyrosine hydroxylase immunoreactivity in the mouse forebrain. J Chem Neuroanat 90:40-48.

Zeyda T, Diehl N, Paylor R, Brennan MB, Hochgeschwender U (2001) Impairment in motor learning of somatostatin null mutant mice. Brain Res 906:107-114. 